\title{
Software engineering in start-up companies: An analysis of 88 experience reports
}

\author{
Eriks Klotins $^{1}$ (D) . Michael Unterkalmsteiner ${ }^{1}$. \\ Tony Gorschek ${ }^{1}$
}

Published online: 21 May 2018

(C) The Author(s) 2018

\begin{abstract}
Context Start-up companies have become an important supplier of innovation and softwareintensive products. The flexibility and reactiveness of start-ups enables fast development and launch of innovative products. However, a majority of software start-up companies fail before achieving any success. Among other factors, poor software engineering could be a significant contributor to the challenges experienced by start-ups. However, the state-ofpractice of software engineering in start-ups, as well as the utilization of state-of-the-art is largely an unexplored area.

Objective In this study we investigate how software engineering is applied in start-up context with a focus to identify key knowledge areas and opportunities for further research. Method We perform a multi-vocal exploratory study of 88 start-up experience reports. We develop a custom taxonomy to categorize the reported software engineering practices and their interrelation with business aspects, and apply qualitative data analysis to explore influences and dependencies between the knowledge areas.

Results We identify the most frequently reported software engineering (requirements engineering, software design and quality) and business aspect (vision and strategy development) knowledge areas, and illustrate their relationships. We also present a summary of how relevant software engineering knowledge areas are implemented in start-ups and identify potentially useful practices for adoption in start-ups.

Conclusions The results enable a more focused research on engineering practices in startups. We conclude that most engineering challenges in start-ups stem from inadequacies in requirements engineering. Many promising practices to address specific engineering challenges exists, however more research on adaptation of established practices, and validation of new start-up specific practices is needed.
\end{abstract}

Communicated by: Forrest Shull

Eriks Klotins

eriks.klotins@bth.se

1 Software Engineering Research Laboratory, Blekinge Institute of Technology, Kariskrona, Sweden 
Keywords Software start-up · Software engineering practices $\cdot$ Experience reports

\section{Introduction}

Software start-ups are important suppliers of innovation and innovative software products (Baskerville et al. 2003), providing products and services that are a significant part to the economy (Startup Compass Inc. 2015). This potential is strengthened further as the use of cutting-edge technologies enable start-ups to develop, launch and evolve software products fast and with very few resources (Baskerville et al. 2003).

A challenge is that most start-up companies collapse before any significant achievements are realized (Tovstiga and Grossmann 2012). This is explained by market conditions, lack of commitment, financial issues or, simply put, a bad product idea. However, product engineering activities takes substantial resources from start-ups, especially in the early stages (Crowne 2002; Giardino et al. 2015). Inadequacies in used engineering practices could lead to under or over-engineering the product, wasted resources, and missed market opportunities.

One of the main qualities of start-ups is their ability to quickly take advantage of new business, market and technology opportunities (Giardino et al. 2014; Bajwa et al. 2017). Decisions, such as what features to build, how and when, belongs to the realm of engineering and have a huge impact on how the start-up responds to new opportunities. For example, certain decisions may hamper flexibility of the product, thus reducing the speed of adapting the product for entering new markets. Taking one sub-optimal decision may have only a small effect on start-up's prospects, however the compound effect of the decisions determines whether the start-up is able to remain on the edge of innovation or is struggling to keep its product running. This is a source of risk and opportunity with potential effects to all aspects of the company.

Yau and Murphy (2013) argue that practices adapted from established companies attempt to solve problems that are not present in start-ups, while ignoring start-up specific challenges, such as time-to-market as the primary goal, and accumulating technical debt (Carmine et al. 2016). Even though similar challenges can be present in established organizations too and addressed by state-of-the-art practices, it is the combination of multiple challenges that makes engineering in start-ups difficult. There is a gap in understanding how these start-up specific challenges influence the engineering process and what engineering practices are suitable for such context (Klotins et al. 2015; Paternoster et al. 2014).

This lack of understanding results in that there are very few, if any, start-up context relevant software engineering processes/methods/models/frameworks (called practices from now on). At the same time, a substantial amount of money is invested in start-up companies. In the first three quarters of 2015 alone, start-up companies received investments of 429 billion USD in the US and Europe (PitchBookData 2015a, b). With an optimistic start-up failure rate of $75 \%$ this constitutes 322 billion USD of capital potentially wasted on building unsuccessful products (Startup Compass Inc. 2015; PitchBook Data 2015a, b). To what extent inadequacies in software engineering practices are responsible or linked to success rate is very hard to judge. However, even if the effect of improved engineering practices only would result in a few percent change in success rate, it would yield significant impact and capital return. Thus, the focus of our study is to explore specifically software engineering in start-ups and pinpoint specific areas for further research that are likely to benefit start-up practitioners. 
Researchers have recognized the importance of software engineering in start-ups. Bosch et al. (2013) and Deakins and Dillon (2005) propose adaptations of iterative and incremental development methods to address engineering challenges in start-up companies. However, this work is preliminary and has not been validated yet in practice (Klotins et al. 2015; Paternoster et al. 2014). Carmine et al. (2016) report on an interview study aiming to understand how start-ups select their product development strategy and how start-ups consider product quality attributes. Giardino et al. (2015) also investigated the key challenges in software start-ups and report that technology uncertainty is the key challenge in software start-ups. However, none of these studies provide a comprehensive answer of what engineering practices are relevant in start-ups.

In this paper we use empirical data from 88 start-up experinece reports to provide the first insight into what engineering knowledge areas are relevant in software start-ups. Our aim is to explore what engineering practices the start-ups report as relevant, how these practices are applied and what results they yield. To analyze the reports we use qualitative data analysis methods (Seaman 1999; Garousi et al. 2016)

To cater for the fact that the experience reports cover also business and marketing aspects, which are tightly intertwined with software engineering aspects, we use a software and business practices taxonomy to support the analysis of the reports. Even though we acknowledge importance of good business, market and other practices, the focus of this paper is strictly on software engineering practices.

The main contribution of this paper is the identification and description of the state-of-practice in software start-up companies, pinpointing to several relevant software engineering areas that need further research. Moreover, we present related work to each relevant software engineering knowledge area, illustrating potentially useful engineering practices for start-ups.

The remainder of this paper is structured as follows: Section 2 presents background and related work and Section 3 introduces the research methodology. The results are presented in Section 4, analyzed and discussed in Section 5. Section 6 concludes the paper.

\section{Background and related work}

\subsection{Software start-ups}

As early as 1994, Carmel (1994) recognizes small software companies being exceptionally successful at innovation and delivery of new products. Termed software start-ups, these companies share many features with small and medium enterprizes such as market pressure, youth and immaturity, and limited resources (Sutton et al. 2000). However, start-up companies are different due their goals and challenges. Contrary to established companies who aim to shape their products to address a known market need, start-up companies attempt to identify an unmet market need and to invent a product satisfying this need (Startup Compass Inc. 2015).

The engineering context in start-ups is characterized by uncertainty, lack of resources, rapid evolution and an immature team among other factors (Sutton et al. 2000). However, the start-up context also provides flexibility to adapt new engineering practices and reactiveness to keep up with emerging technologies and markets (Giardino et al. 2014).

Product related issues are reported as the key challenge in start-up companies (Giardino et al. 2015). However, recent literature mapping studies identify a lack of research in the area from a software engineering perspective (Klotins et al. 2015; Giardino et al. 2014). 
Moreover, most publications to date are experience reports lacking in-depth analysis and rigorous research methods on empirical data (Klotins et al. 2015).

Despite attempts to explore the start-up phenomenon, only a few studies specifically focus on understanding how software engineering is done in start-up companies. Yau and Murphy (2013) and Sutton Sutton et al. (2000) recognized that engineering practices aimed at established companies are not suitable for start-ups. As a result, various models for software development in start-up context were proposed (Deakins and Dillon 2005; Bosch et al. 2013; Zettel et al. 2001), however there is very little evidence of application and validation of these models (Klotins et al. 2015).

An agenda to specify important research topics regarding software engineering in start-ups has been created by the Software Start-up Research Community (Abrahamsson et al. 2016). Among other topics, engineering practices in start-ups is identified as an important research area.

Rafiq and et al (2017) and Melegati et al. (2016) have studied requirements engineering practices in start-ups and provide an insight into how product ideas evolve and what practices are used to connect founders' vision with customer needs.

Crowne (2002) proposes a start-up life-cycle model and identifies goals and the key challenges at each of the life-cycle phases. According to the model, in the first phase a company develops an early version of the product. The goal of the second phase is to improve quality of the product until it can be commissioned with little effort. In the third phase, the company grows and conquers the market. In the fourth phase the company matures into an established organization. However, there is no detailing on the use or adaption of engineering practices, or their evolution over time and phases.

Giardino et al. present a behavioral model aimed at explaining start-up failures. They argue that a start-up must first explore the problem domain and then validate a proposed solution, however mismatching validation activities with exploration activities could lead to a failure (Giardino et al. 2014). This is directly related to engineering practices such as overall requirements engineering or scoping.

Olsson and Bosch (2015) identify challenges of using customer feedback in large software-intensive product engineering. A case study reveals that to compensate for inadequate utilization of user feedback, companies invent requirements and steer product direction by "gut feeling". Invented requirements lead to a large amount of unused and incorrectly implemented features contributing to product failure (Olsson and Bosch 2015).

Software engineering in start-ups shares many similarities with companies using agile development practices, such as iterative development, empowered small team, and ongoing planning (Ramesh et al. 2007; Chow and Cao 2008). However, customer involvement, which is one of the key agile principles, is difficult to establish as start-up companies lack a distinct set of customers. Hence, start-ups operate in a market-driven environment (Dahlstedt et al. 2003). In a market-driven environment, requirements are often invented and validated through frequent product releases (Dahlstedt et al. 2003; Alves et al. 2006).

There has been a substantial work to identify general operating practices for start-ups, such as The Lean Start-up (Ries 2011) and Customer Development Model (Blank 2013a). However, there exist very few peer-reviewed studies in software engineering fora, with May (2012) being the exception, reporting on the application of said practices. Therefore, it remains to be explored to what extent these or any other practices are adopted by start-ups.

\subsection{Scope of software engineering in start-ups}

Sutton et al. (2000) argues that start-up companies are sensitive to many influencing factors, such as customers, partners, changes in technologies and markets. The developed software is 
often a component of another product and which is an essential part of the start-up company itself (Baskerville et al. 2003). Therefore, software engineering in start-ups must be studied jointly with its dependencies and influences to other areas of a start-up (Broy 2006).

The interrelation of software engineering, product development and other areas in an organization is recognized by ISO/IEC 42010:2011 which provides a definition of softwareintensive system as: "any system where software contributes essential influences to the design, construction, deployment, and evolution of the system as a whole to encompass individual applications, systems in the traditional sense, subsystems, systems of systems, product lines, product families, whole enterprizes, and other aggregations of interest" (IEEE 2011).

To fully understand the importance of software engineering in start-ups we widen our field of view and capture other concepts that influence or depend on software engineering. To define the scope for this study we use a taxonomy, further elaborated in Section 2.3.

\subsection{Software engineering and business practice taxonomy}

A taxonomy is useful for categorization and mapping of knowledge, facilitating identification of gaps and boundaries of a phenomenon (Šmite et al. 2014). Seaman (1999) suggests to use of preformed codes, e.g. a taxonomy, to facilitate coding in qualitative studies. Hence, to support the identification of software engineering and other relevant practices we developed a taxonomy listing knowledge areas and practices for start-ups - the SoftWare and Business Process, hereinafter the SWBP, taxonomy. The taxonomy consists of software engineering knowledge areas as defined by SWEBOK, and several business aspects oriented knowledge areas inspired by Osterwalder et al. (2005) and Zachman (2003).

Even though SWEBOK is not specifically designed for software start-up companies and lacks emerging areas of software engineering, such as value-based software engineering (Boehm 2003; Azar et al. 2007) and market-driven requirements engineering (Dahlstedt et al. 2003; Karlsson et al. 2007), it promotes a consistent view on software engineering, and is well recognized within software engineering community (Sicilia et al. 1990; Budgen et al. 2008).

Other frameworks, such as CMMI (Product Team and Team 2010) and SPICE (Dorling 1993), are oriented toward software process identification, assessment and improvement. However, as indicated by Giardino et al. (2014) and Sutton et al. (2000), start-up organizations are very immature in a process sense, thus identification of engineering processes could be difficult.

Several business practice frameworks, such as ABPMP BMP CBOK (Abpmp 2009), papers by Osterwalder et al. (2005) and Zachman (2003), aim to map and categorize business practices, however none of them is specific to start-up companies (Blank 2013b). Due to youth and immaturity of start-up companies, traditional business processes are difficult to identify. Therefore, we created a simplified business practice taxonomy based on ABPMP BMP CBOK. The exact categories of the taxonomy are provided in the supplementary material. ${ }^{1}$

We use the unified SWBP taxonomy to identify and categorize all relevant practices to explore software-intensive product development in start-ups.

\footnotetext{
${ }^{1}$ http://eriksklotins.lv/files/exp-reports-study-supplemental-material.pdf
} 


\section{Research methodology}

\subsection{Research questions}

Our research goal is to investigate how software engineering is practiced in start-up companies and how software engineering contributes to other areas of a start-up, such as business and marketing. To break down the research goal further, we formulate the following research questions:

RQ1: What software engineering knowledge areas do software start-up companies consider most relevant?

We explore what knowledge areas and specific categories in software engineering are of interest for start-up companies. This enables to focus further research on the areas that have the potential to actually support software start-up companies.

RQ2: How are the identified knowledge areas applied in start-ups?

We explore how the identified knowledge areas (RQ1) are implemented in start-up companies. This increases the understanding of how, or whether at all, software engineering knowledge and practices are applied.

RQ3: What are the relationships between different knowledge areas?

We explore the relationships between the applied practices to understand how practices and knowledge areas affect each other. The understanding of the relationships enables the analysis of how significant each practice is in context of other practices.

RQ4: What practices are missing to support software engineering in start-up companies?

Having identified relevant knowledge areas (RQ1), how the knowledge areas are implemented in terms of practices (RQ2), and relationships between the practices (RQ3) we identify gaps in applied practices. We review related work to identify practices that could be useful for adaptation in start-ups.

\subsection{Data sources and collection}

We use a collection of start-up experience reports (cbinsights.com 2015) as the data source. The reports represent a primary data source, i.e. we perform original analysis of data, and we perform third degree analysis, i.e. we independently analyze artifacts that are already available (Lethbridge et al. 2005).

The experience reports describe lessons-learned from start-up companies, written by one of the participants after critical events occurred in the start-up, for example, a key person leaving a company, a product launch, a buyout or closure of the company. Even though the reports represent "multi-vocal literature", i.e. are unstructured and vary in length, focus and style (Ogawa and Malen 1991; Tom et al. 2013), they provide a rich insight on how start-ups perceive and approach software-intensive product engineering (Garousi et al. 2016). The reports cover a much broader scope than just product engineering thus providing insights how product engineering is influenced by and what influence engineering has on other factors in start-ups.

We screened the collection to remove inaccesible or otherwise irrelevant reports, prior to the detailed analysis, according to the following criteria:

1. The report is inaccessible, for example, the link provided in the website to the actual report is broken.

2. The report clearly does not describe experience from a start-up company, for example, the report describes experiences from an established company. 
3. The report clearly does not describe experiences from a software start-up, i.e. the startup does not do software engineering in any way.

From the initial set of 93 reports, 5 reports were removed and 88 remained for further analysis. Secondary data sources are start-up profiles (crunchbase.com 2015) that record company track length, geographical location and members of their founding teams. Figure 1 illustrates how each data source contributed to answering the stated research questions.

We created a simple database tool to import, store and maintain traceability between different pieces of data. Prior to storing, we trimmed irrelevant information, i.e. ads, unrelated pictures, links, from the reports and split the reports into chunks by a paragraph for further analysis. A paragraph was selected as unit of analysis as it is large enough to convey a complete statement and small enough to maintain traceability. The splitting was first done with an automated tool and later manually revised. The final chunks were 1 - 16 sentences long.

\subsection{Analysis design and execution}

To analyze the reports we use qualitative data analysis methods, that is, different types of coding and themeing of concepts (Seaman 1999; Saldaña 2010). Figure 1 illustrates the used data sources, the three analysis steps, the output and how it answers the research questions.

In step 1 we apply provisional coding we explore the data and identify and categorize statements in the reports related to software engineering or business development (Saldaña 2010). We associate statements in the reports with preformed codes from the SWBP taxonomy (see Section 2.3), as suggested by Seaman (1999).

Our study is specifically angled toward software engineering practices and their connections to business knowledge areas, thus the SWBP taxonomy supports identification of relevant data to answer our research questions. We associate statements in the reports with a knowledge area, category or a sub-category from the taxonomy. More explicit statements are mapped to sub-categories, while more general statements are associated with a knowledge area in general. Mapping to the lowest level enables analysis both on knowledge area level and a more specific analysis of what sub-categories in a particular knowledge area are addressed. To code ambiguous statements we use simultaneous coding (Saldaña 2010), mapping the statement to multiple categories of the SWBP taxonomy. To further describe each identified statement we added two magnitude sub-codes (Saldaña 2010). The first subcode captures the impact direction of a described practice. We use the values "positive", "unknown" and "negative" to capture the report's author own reflection on the impact of a practice. For the second sub-code we use the values "product", "business" and "both" to

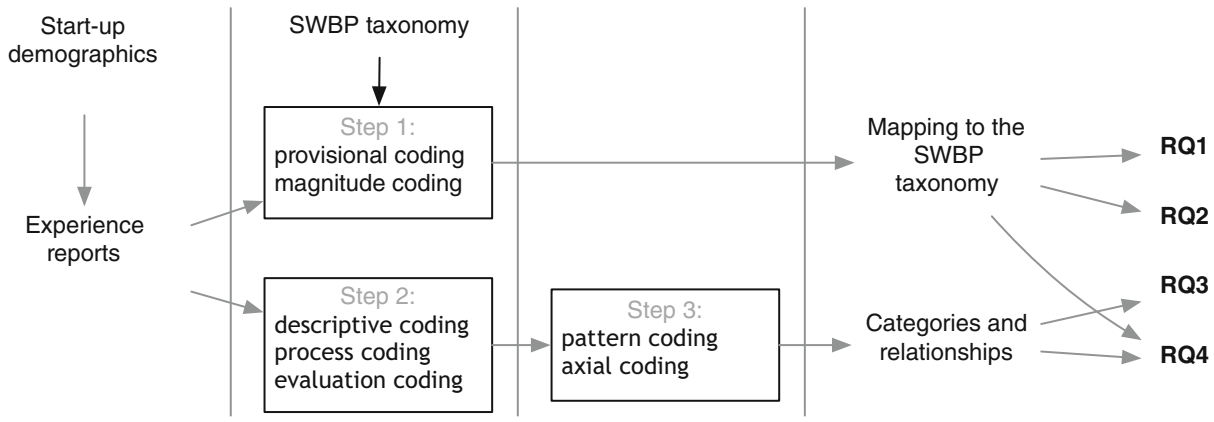

Fig. 1 Overview of the coding process and research questions 
capture the affected object. The scope for each code is a sentence in a report. Sub-codes are added on top of each code.

In step 2 we perform another pass on each report and look at the reported experience as a whole to identify key concepts, analysis points, leading to gains or losses in software engineering or business development. Looking at the reporter's opinion on what activities had significant impact on software engineering, we attempt to identify contextual factors and activities causing the high impact situation. We make use of descriptive (to summarize), process (to capture ongoing action) and evaluation (to assess the situation) coding (Saldaña 2010) jointly to capture analysis points in a report. Through analysis of the described situation we aim to differentiate between reported symptoms (e.g. running out of resources) and actual causes (e.g. poor resource planning due to lack of experience). Coding in this step is open, i.e. we let codes to emerge naturally without use of the taxonomy. Examples of coding in the steps 1-2 are provided in the supplementary material. ${ }^{2}$

In step 3 we apply pattern and axial coding (Saldaña 2010) to combine similar analysis points and to establish relationships between emerging categories. As similar activities and contextual factors recur in the data, we group them under a candidate category. We merge, split and update the candidate categories during the coding process. A category gains full category status when its category description allows understanding of characteristics, conditions, consequences and interaction of the expressed concept. To understand how different concepts influence each other we further employ axial coding (Corbin and Strauss 1990) looking for possible causes and consequences across all analysis points forming each category. This enables deeper understanding of a concept and provides multiple explanations for its emergence and impact. Field memos in a form of white board drawings, notes and mindmaps were created to record any discoveries in the data. During the analysis we kept track of what specific statements from reports actually support the category or the relationship and continuously update a category description. We use this information to further develop or discard patterns emerging from the data.

Saldaña (2010) suggests to connect categories with underlying concepts by applying theming portions of data. Where possible, we associate the categories with practices from the the SWBP taxonomy. The association connects the categories to state-of-the-art enabling further elaboration and exploration of a category.

\subsection{Answering the research questions}

We answer RQ1 (What software engineering knowledge areas do software start-up companies consider most relevant?) by counting how frequently each knowledge area is discussed in the reports. Some reports repeatedly address the same issue resulting in multiple identical codes and impact sub-codes. Such repeated codes are useful for further qualitative analysis, however are counted only once in the quantitative analysis in order not to inflate the importance of a knowledge area. By differentiating between the reported positive or negative impact on software engineering or business development aspects, we identify potential inadequacies in the application of knowledge in that particular area, specific for the software startup context. The analysis of this research question is presented in Section 4.2.

We answer RQ2 (How are the identified knowledge areas applied in start-ups?) by summarizing reported practices relevant to each knowledge area.

\footnotetext{
${ }^{2}$ http://eriksklotins.lv/files/exp-reports-study-supplemental-material.pdf
} 
We answer RQ3 (What are the relationships between different knowledge areas?) by developing a graph illustrating relevant knowledge areas and their relationships. By looking at the number of data-points we identify the most important relationships for further exploration. We discuss the relationships in context of related work.

We answer RQ4 (What other practices are missing to support software engineering in start-up companies?) by identifying the most interconnected categories and their relationships in Fig. 9 (RQ3). We assess the central categories in context of the related categories, examine if the answer to RQ2 suggest any particular practice pertaining the relationship, and review related work for candidate practices.

\subsection{Validity threats}

We present four categories of validity threats as proposed by Runeson et al. (2012).

\subsubsection{Construct validity}

Construct validity is concerned with to what extent the studied operational measures represent what the researcher is attempting to investigate (Runeson et al. 2012).

A possible threat is that we may fail to recognize relevant practices in the reports. To address this threat we use a taxonomy to support identification and categorization of statements from the reports.

We use the SWBP taxonomy as a framework to identify and categorize statements from the reports.

However, the SWBP taxonomy is partly based on SWEBOK and may not up to date with emerging concepts in software engineering such as value based software engineering (Boehm 2003; Azar et al. 2007) and market-driven requirements engineering (Dahlstedt et al. 2003; Karlsson et al. 2007). To address the threat that some important aspects are missed due to the lack of a comprehensive taxonomy we use two separate coding strategies, i.e. provisional coding (based on a taxonomy) and analysis points (independent from any taxonomy).

Due to lack of detail or terminology differences between the reports and the taxonomy it could be challenging to map certain statements to specific software engineering practices. We address this threat by a) applying multiple codes to the same statement to capture multiple interpretations and b) mapping the statements to different levels of the taxonomy. As a possible consequence of multiple codes per statement, we may incorrectly estimate the number of statements addressing a particular category of the taxonomy. However, multiple codes also enable identification and analysis of closely related and overlapping practices.

Another threat to construct validity is a possible bias stemming from the nature of subjective experience reports. In their essence, the reports are self-evaluations by the authors. They may have overlooked their own shortcomings, e.g. a lack leadership or technical skills, and rationalized their experience with external circumstances (Pronin et al. 2002). However, due to relatively large sample and diverse population we likely cover different personality types, therefore minimizing this threat (Feldt et al. 2010). An alternative solution could be to use grounded theory (Corbin and Strauss 1990) and study a smaller sample in more detail, thus strengthening the internal validity at the expense of generalizability.

Even though we applied multiple remedies to address the threats that stem from the nature of the data we have collected, we are conservative in the conclusions that we draw from the data and analysis. 


\subsubsection{Reliability}

This aspect is concerned with the extent to which the results and analysis are independent from the specific researchers (Runeson et al. 2012).

We address reliability by ensuring transparency and traceability throughout our data collection and analysis, providing a detailed description of the applied research method. All analyzed experience reports are provided as supplemental material. ${ }^{3}$

We have kept traceability information throughout our results and analysis linking specific conclusions with supporting statements in the experience reports.

\subsubsection{Internal validity}

Internal validity is threatened when a researcher is investigating one factor affecting another factor and there exists a third, unknown factor, that confounds the studied relationship without the researchers knowledge (Runeson et al. 2012).

A possible threat here is the single researcher bias in the coding process. To address this threat we applied researcher triangulation. Twice in the coding process, at the beginning and later in the process, selected reports were analyzed independently by three researchers and the results discussed to identify and eliminate any individual biases. In addition to the triangulation, intermediate results were discussed among the researchers and compared to state-of-the-art.

\subsubsection{External validity}

External validity concerns the ability to generalize the result of research efforts to industrial practice and to what extent the results are of interest outside the investigated case (Runeson et al. 2012).

A potential threat to external validity is sampling. For our study we have used convenience sampling and studied a relatively large number of cases from different geographical regions, market segments, team composition variations, product types, and consider both successful and failed cases.

The majority of start-up cases in our sample (63 of 88, 72\%) are closed companies. As elaborated in Section 4.1 and Fig. 4, this proportion is representative of the whole startup population which is nevertheless biased toward failed start-ups. Therefore we avoid to present any prescriptive advice that derives from the studied companies.

\section{Results}

\subsection{Overview of the data set}

We have analyzed experience reports of 88 start-ups. The sample of companies is diverse in developed products, geographical location and founders experience. We attempt to estimate to what extent the studied sample is representative to the whole population.

\footnotetext{
${ }^{3}$ http://eriksklotins.lv/files/exp-reports-study-supplemental-material.pdf
} 


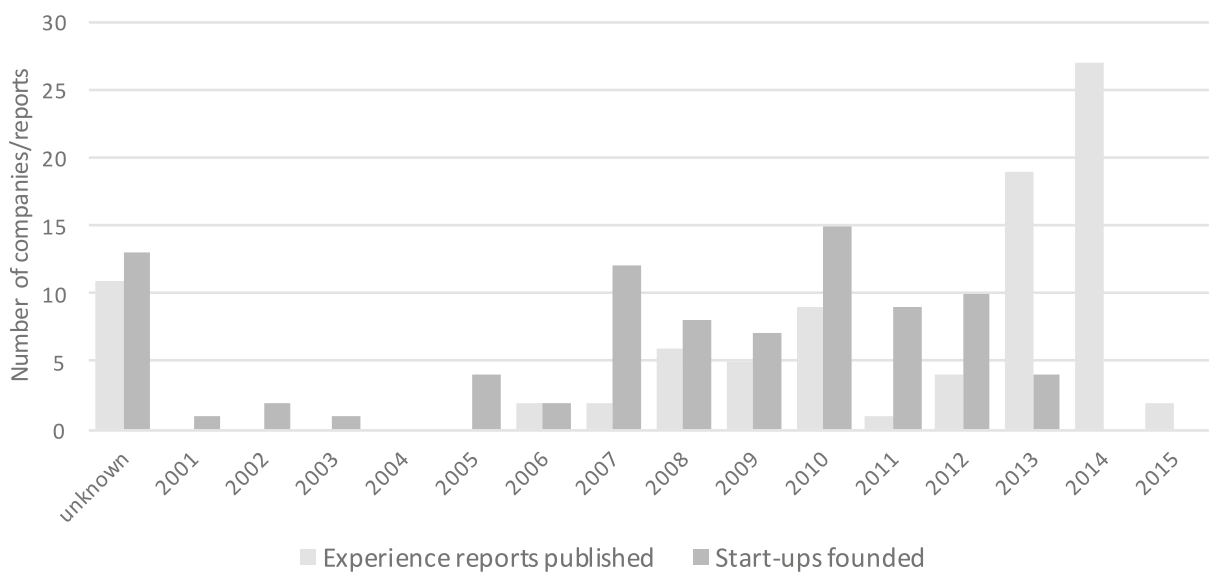

Fig. 2 Overview of the start-up founding and report publishing time

Figure 2 shows an overview of when companies in our sample were founded and when the reports were published. A total of 56 out of 88 companies (63\%) have provided information on their founding and closure time. The companies were founded between 2001 and 2013 (Median = 2010). For 77 companies we were able to identify when they have published their experience report. The reports were published between 2006 and 2015 $($ Median $=2013)$.

Figure 3 summarizes the operational track length of the companies, which varies between less than a year to 8 years. The majority of companies for which we know the track length, 38 out of 56 companies (68\%), have operated between one and three years.

A total of 65 out of 88 companies $(73 \%)$ have provided location information. Within this group, 48 out of 65 companies (74\%), were located in US, 13 companies were located in Europe, and the rest were located in India, Australia and Canada.

In Fig. 4 we summarize status of the studied companies. In contrast to what is stated on the website (cbinsights.com 2015), some of the companies have re-emerged, continue

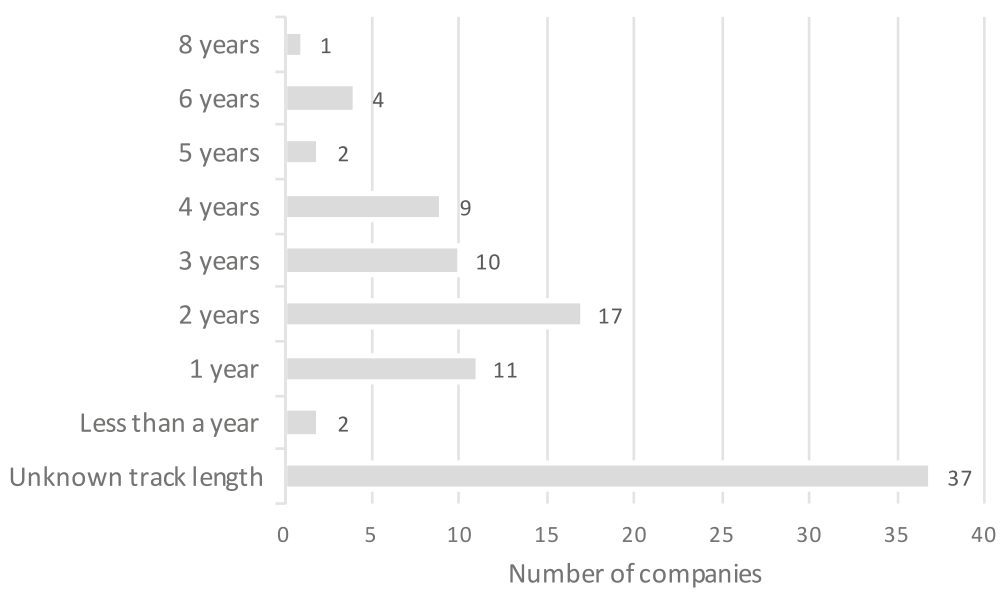

Fig. 3 Overview of the operational track length 


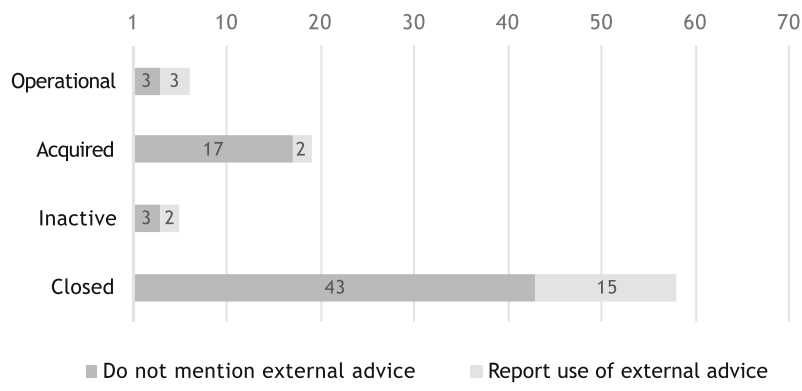

Fig. 4 Outcomes of the companies and impact of external advice

working, or were acquired by other companies, thus can be considered as relative successes. Analyzing the reports and publicly available information, as of June 2016, we have identified different outcomes of the evaluated companies. We distinguish between the following:

- Operational: The company is still in operation. This category also includes companies that have re-emerged with similar products. Also, companies that have pivoted, e.g. redesigned their product. Examples of such companies are:

- GroupSpaces, available at http://groupspaces.com/

- Pumodo, available on iTunes as 'Champion - Football Livescore, League and Cup Action'

- PatientCommunicator, available at http://patientcommunicator.com/

- Acquired: The company, the team or its intellectual property was acquired by another company. Examples of such companies are:

- Decide, acquired by eBay in 2013

- PackRat, acquired by Facebook in 2011

- ReadMill, acquired by Dropbox in 2014

- Inactive: The company has ceased any active sales or commercial product development activities, however the product is still available to users. This category also includes inactive companies that have made their products available as open-source.

- Closed: The company has ceased any operations, the product is not available to users.

In Fig. 4 we distinguish between companies that have reported participation in incubator programs or otherwise received an external expert advice, e.g. consulted with investors or mentors. There is no clear tendency of external advice being a determinant to company survival, acquisition or close-down.

In the general start-up population, the failure rate is about $75 \%$ (Startup Compass Inc. 2015). Companies that are closed down or inactive we consider as failed start-ups. Companies that are operational or have been acquired we consider successes. As Fig. 4 shows, in our sample 6 companies are still operational and 19 have been acquired, resulting in a total of $25(28 \%)$ companies that can be seen as successful, while $58(66 \%)$ of the companies have been closed, thus can be considered as failed. Although we do not know financial details of the operational and acquired companies, the percentage of failed companies in the general population (75\%), and closed and inactive companies in our sample (72\%) is similar. 


\subsection{Knowledge area overview}

As a result of provisional coding (see Step 1 in Fig. 1), we identified and mapped 876 statements from the experience reports to the SWBP taxonomy. Saldaña (2010) suggests to look into how many reports mention a particular code instead of a total count of codes in the dataset. Therefore, we removed identical codes per report from further frequency analysis. After this filtering our dataset contains 755 codes.

We use the number of codes to illustrate what knowledge areas and their subcategories are common in the reports and what rarely occurred (Saldaña 2010). There could be several explanations why a knowledge area is discussed in an experience report. One is that activities associated with a particular knowledge area were conducted and had some interesting effect. This explanation suggests that a knowledge area is relevant for start-ups either because it is useful (and yields positive results), or requires adaptation for use in start-ups (if the knowledge area was applied with good intentions but provided unanticipated results). Another explanation is that a company did not apply a potentially useful knowledge area, however reflected on their mistake in a report. This suggests that a knowledge area could be useful in hindsight.

Figure 5 shows a summary of this analysis. The horizontal axis shows the number of reports mentioning a particular knowledge area; direction (positive or negative) indicates impact. Differently shaded bars show whether the impact is discussed as having impact on business development, software engineering or both. The total length of a bar indicates the total number of codes referring to particular knowledge area. Note, that a knowledge area could be discussed from various aspects in a single report, thus resulting in multiple different codes per same knowledge area. The number of statements discussing a particular knowledge area but not specifying any impact are shown in circles between the bars. In total, 209 (28\%) statements address software engineering aspects, and 296 (39\%) address business aspects of start-ups.

As Fig. 5 shows, software requirements engineering, software design and professional practice are the top three most discussed knowledge areas in relation to inadequacies in product engineering. Software engineering process, computing foundations, mathematical foundations and the engineering foundations knowledge areas are not discussed at all in the reports.

Figures 6, 7 and 8 illustrate what specific subcategories of requirements engineering, software design and engineering professional practice are discussed in the reports. From the requirements engineering knowledge area, requirements validation, analysis and elicitation are the most discussed sub-categories. From the software design knowledge area, the most discussed sub-category is user interface design. From the software professional practice the most discussed sub-category is group dynamics and psychology.

\section{Analysis and discussion}

In this section we synthesize our analysis into the software engineering knowledge areas reported by startups to answer the remaining three research questions. First, we report how a knowledge area is applied, what specific practices are mentioned and what specific challenges are discussed in the reports in relation to the knowledge area (RQ2). Second, we explore what relationships between knowledge areas are reported to understand how software engineering knowledge areas influence each other (RQ3). Third, we look into related work from similar engineering contexts, compare challenges between start-up and 
SW Requirements Engineering

SW Design

SW Construction

SW Testing

SW Maintenance

SW Configuration Management

SE Management

SW Engineering Process

SE Models and ethods

SW Quality

SE Professional Practice

SE Economics

Computing foundations

Mathematical foundations

Engineering foundations

Develop Vision and Strategy

Market and sell products and services

Manage customer service

Develop and manage human capital

Manage Financial Resources

Manage external relationships

Business assistance and training

Legal structure and protection

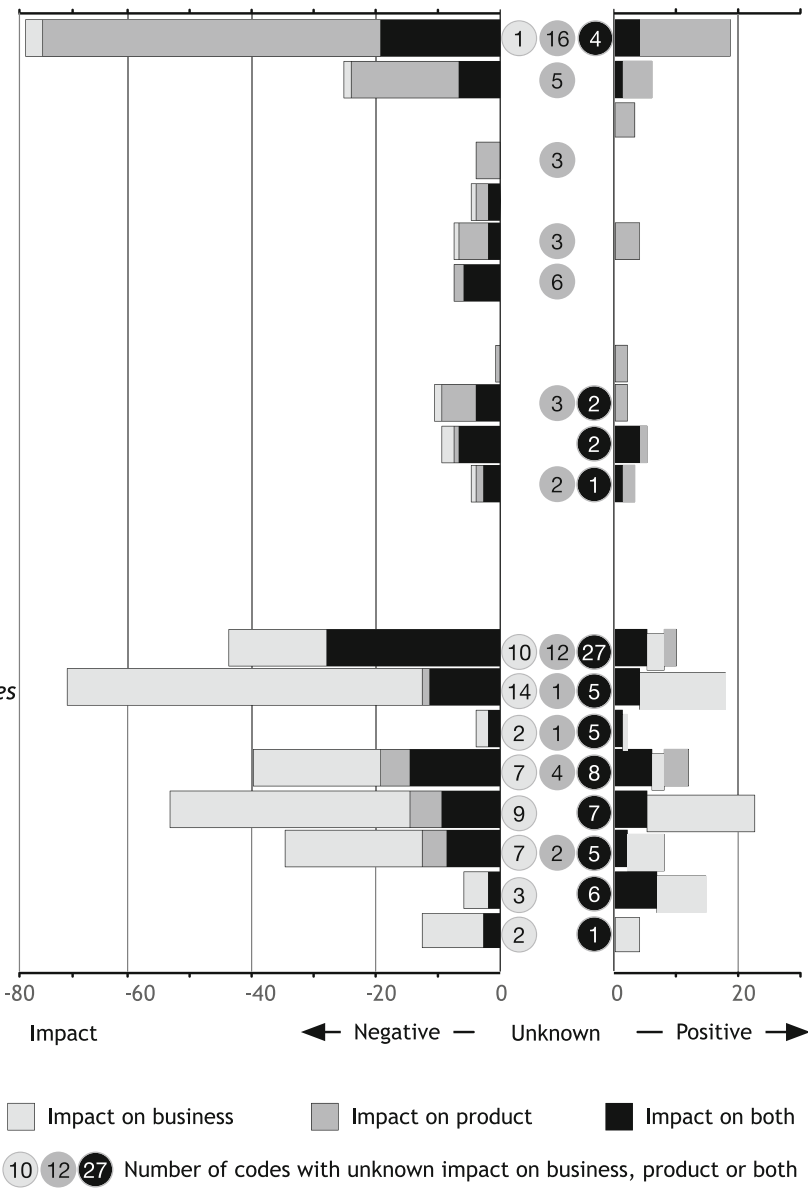

Fig. 5 Overview of the number of statements associated with knowledge areas

other engineering contexts, and identify potentially useful practices to solve engineering challenges in start-ups (RQ4).

Figure 9 shows key knowledge areas and their relationships of software-intensive product engineering in start-up companies (identified by applying pattern and axial coding as explained in Section 3.3). In Fig. 9, boxes represent knowledge areas, arrows denote a relationship between knowledge areas. A relationship indicates that a parent category provides input, i.e. information, to a child category. In further subsections we discuss the knowledge areas and their relationships in detail.

To support traceability between our analysis and data in the reports, we use references to the original data. The references are represented by identifiers in curly braces after a statement, formatted in the following way: $\mathrm{C}<\{$ company\# $>-<$ chunk\# $>\}$. The identifiers refer to the supplementary material available online. ${ }^{4}$

\footnotetext{
${ }^{4}$ http://eriksklotins.lv/files/exp-reports-study-supplemental-material.pdf
} 
SW Requirements Fundamentals

Requirements Process

Requirements Elicitation

Requirements Analysis

Requirements Specification

Requirements Validation

Practical Considerations

Software requirements tools

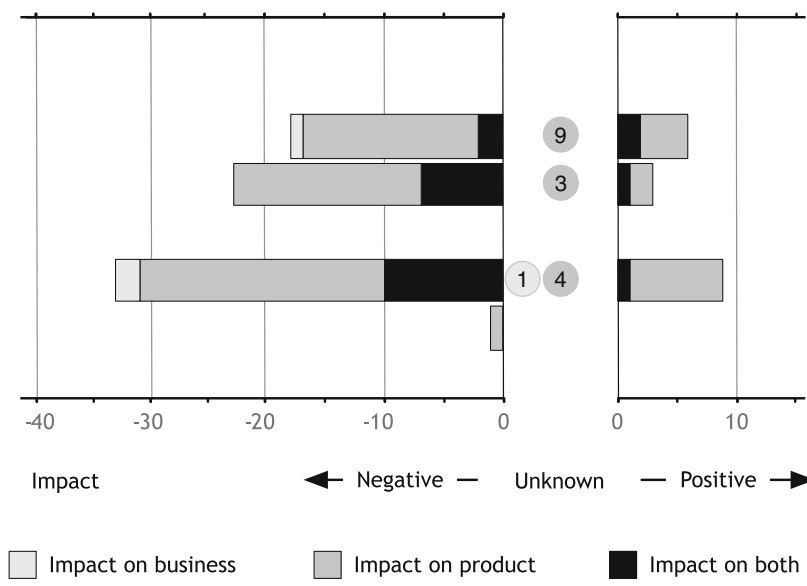

(1) Number of codes with unknown impact on business or product

Fig. 6 Breakdown of the software requirements engineering knowledge area

SW design fundamentals

Key issues in SW design

SW structure and architecture

User interface design

SW design quality analysis and evaluation

SW design notations

SW design strategies and methods

SW desing tools
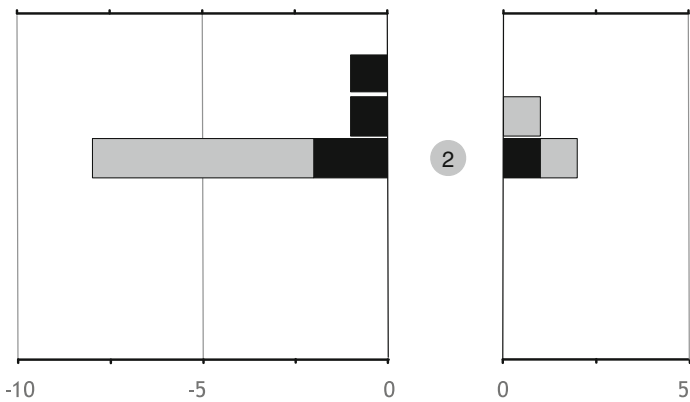

Impact

Negative - Unknown - Positive

Impact on business

Impact on product

Impact on both

(2) Number of codes with unknown impact on product

Fig. 7 Breakdown of the software design knowledge area

Professionalism

Group Dynamics and Psychology

Communication Skills
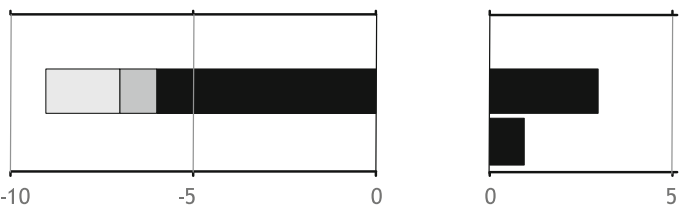

Impact

Impact on business
Negative - Unknown

Impact on product
- Positive

Impact on both

Fig. 8 Breakdown of the software professional practice knowledge area 


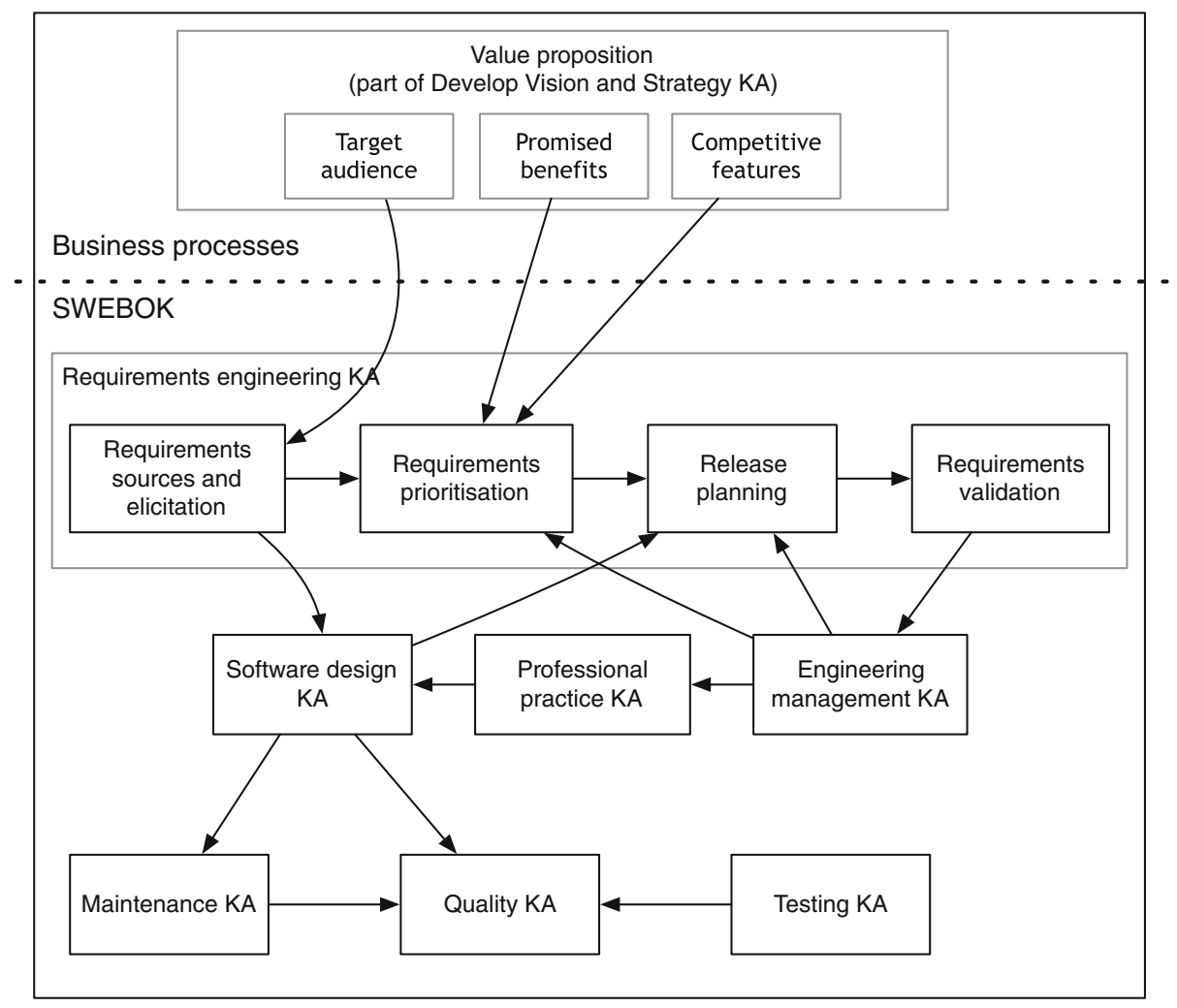

Fig. 9 Software engineering categories and their relationships

\subsection{Develop vision and strategy knowledge area}

Our analysis shows the process of identifying a product value proposition as a bridge between marketing and engineering aspects of a product. Value proposition provides an essential input for starting software requirements engineering activities. The value proposition is a structured description of a product idea. It outlines what is the target audience for the product is, what benefits the product aims to deliver, and what the competitive features of the product are (Carlson and Wilmot 2006).

The reports discuss identification of the value proposition as an iterative process where the initial formulation is brainstormed, and then improved by means of market research, customer interviews, prototype demonstrations and similar activities \{C2-50, C11-10, C24-3, C29-63, C37-30, C48-5, C50-9, C52-26, C63-45, C64-33, C67-45\}. The value proposition bridges the gap between market research (with a goal to explore market potential of the product) and requirements engineering (with a goal to identify a feasible solution) (Hague et al. 2004; Dahlstedt et al. 2003).

As shown in Fig. 9 a structured formulation of the product idea helps to identify specific goal level requirements which then are broken down into more specific functional and quality requirements by requirements engineering activities. Target audiences help to identify stakeholders for requirements elicitation activities. Inadequacies in the value proposition may hinder requirements engineering activities. For example, an unclear overall product 
goal makes it difficult to specify criteria for requirements prioritization, release scoping and for identifying stakeholders.

\subsection{Requirements engineering knowledge area}

Software requirements engineering is a set of activities to capture the needs and constraints placed on a software product, and to identify a feasible solution that contribute to solving a real-life problem. Therefore, requirements engineering can take both problem and solution oriented view (IEEE 2014).

As shown in Fig. 5, requirements engineering is the most discussed software engineering knowledge area in the reports. Further analysis of statements from the reports, illustrated in Fig. 9, suggests that requirements engineering is the central software engineering activity in start-ups.

Start-up companies operate in a market-driven environment, thus initial requirements are invented by a start-up team (Dahlstedt et al. 2003; Ambler 2002). In similar contexts outside start-ups, requirements are validated by internal feasibility reviews, interviews, surveys, crowd-funding success and other techniques that are applicable in the pre-development stage (Fabijan et al. 2012; Ambler 2002). Requirements negotiation takes place to prioritize what features to implement next (Tingling and Saeed 2007).

The experience reports suggest that start-ups use a similar approach to requirements engineering. Software is developed in short iterations aimed to implement and validate a slice of requirements. Results from the validation are used as input for subsequent iterations. As Company \#1 reflects on quickly building a prototype, testing it and only then undertaking more extensive mobile application development:

"We had a mobile website prototype in front of users within a week and iterated based on that before building out the native [mobile application] version."

Requirements engineering drives the software development process by helping to acquire domain knowledge, explore problem domain, and to identify potential solutions (Hofmann and Lehner 2001; IEEE 2014). As put by Company \#66:

"One of the key lessons I learned is that great startups have a blindingly obvious, ideally really large and painful problem that the company is trying to solve. Solving

this problem should drive almost every decision in the startup."

Exploring the problem domain and user needs is one of the key practices in early stage startups (Crowne 2002; Churchill and Lewis 1983). Our findings are consistent with Hofmann and Lehner (2001) who argue that inadequacies in requirements engineering are the single largest cause of software project failure.

In the following subsections we discuss sub-categories of the requirements engineering knowledge area.

\subsubsection{Requirements sources and elicitation}

This category represents practices to collect requirements and to identify sources from where engineers can collect requirements (IEEE 2014; Dahlstedt et al. 2003).

The reports suggest that start-ups operate in a market-driven context and that the initial requirements are derived from the product value proposition. Interviews, surveys, observations and demonstration of prototypes are reported as methods to adjust goals, discovering new requirements, and to validate existing requirements $\{\mathrm{C} 1-45, \mathrm{C} 14-20, \mathrm{C} 29-2, \mathrm{C} 48-5$, C50-9, C59-24, C75-4, C79-102, C86-10\} 
The data from the experience reports suggests also that start-up teams use local businesses, people from their social network and even their teams as requirements sources. Similar products, industry standards and regulations, and partnership agreements are discussed as important requirements sources in addition to customer feedback. Examination of similar products is reported as useful to identify base functionality of a product and to spot opportunities for innovation \{C06-12, C1-45, C14-8, C14-20, C33-73, C39-10, C50-8, C61-43, C69-6, C75-4, C79-102, C86-10\}.

The reports suggest that the utilization of customer feedback depends on access to requirements sources and interviewer's skill to discover actual customer needs. The access could be limited by, for example, physical distance and inadequacies in identifying potential customers. Mistaking curious people for potential customers can lead to false requirements hindering the product's market potential. Some companies report testing customer interest by asking for an upfront payment $\{\mathrm{C} 14-34, \mathrm{C} 21-7, \mathrm{C} 02-25\}$. As Company \#14 states:

"I think we did not understand that the real purpose of selling was validation (or invalidation) and had the 'always be closing' mindset at a too early stage of the company. Later, I have been joking that during the validation process, if customers don't buy, you should open a champagne bottle and celebrate that you found one way that didn't work and are now a lot closer to success."

The start-up companies reflect on the importance of early customer feedback and the dangers of not using customer input in the requirements engineering process. Even though gathering of customer input is discussed as difficult due to a physical distance and vague understanding of the target market, customer input is reported as an essential part of requirements engineering. Companies that have neglected early customer feedback report poor product reception in the market and wasted resources on developing unwanted features, often leading to the company's collapse $\{\mathrm{C} 03-10, \mathrm{C} 22-4, \mathrm{C} 35-23, \mathrm{C} 50-8, \mathrm{C} 52-20, \mathrm{C} 34-2$, C59-24, C75-4, C75-17, C75-19, C76-11, C78-15, C78-19, C86-10, C88-4\}.

A commonly reported difficulty is to create an engaged community of early customers of the product. This community facilitates requirements elicitation, validation and other activities were direct customer feedback is essential. The reports suggest that initially a person may show genuine interest in the product, however, if the product does not solve an actual problem for the customer, the interest fades away quickly \{C06-6, C35-20, C52-22, C59-7, C65-16, C67-38, C69-6, C82-16, C83-6\}.

The reports suggest that misuse of customer feedback stems from difficulties to identify and access requirements sources, i.e. customers, and poor elicitation methods, for example asking the wrong questions $\{\mathrm{C} 4-22, \mathrm{C} 4-72, \mathrm{C} 59-7, \mathrm{C} 59-24, \mathrm{C} 61-43, \mathrm{C} 79-102, \mathrm{C} 83-6\}$. As Company \#2 reflects:

"People compliment you on the idea because they believe it will be so useful for people other than themselves. i.e., they get into advisor mode."

Discussion As shown in Fig. 9, using value proposition to identify concrete requirements sources and software requirements is one of the first steps in product engineering activities. Inadequacies in value proposition and requirements engineering activities could hinder any further engineering activities. Unclear quality and functional requirements lead to over or under-engineering of the product.

Identification and access to useful requirements sources is essential for requirements elicitation (Mitroff 1983). In a market-driven context, a company must solve the practical 
problem on how to select a manageable number of users, e.g. early customers, to perform requirements elicitation activities.

Pacheco and Garcia (2012) suggest to classify all likely users and to study all of the user classes to identify their role in the product. Pruitt and Grundin (2003) suggest that the use of superficial characters representing users of the product, i.e. 'personas', helps to identify different user groups and to facilitate discussion around the requirements. The personas could be created with help of a small group of customers or domain experts and further detailed with interviews, surveys and ethnographies to create more detailed descriptions of the users and their needs (Miller and Williams 2006; Pruitt and Grundin 2003). This lightweight practice could be useful for start-ups when actual customers are not readily available.

Fabijan et al. (2012) suggest different customer feedback collection techniques useful at different development stages. Since access to actual users for face-to-face interviews is usually limited, start-ups could use indirect requirement sources such as listing the product idea on a crowd-funding website (Fabijan et al. 2012; Pruitt and Grundin 2003), validating the product idea and discover new requirements with less effort.

Due to practical restrictions, only a limited number of potential users can be involved in elicitation and any requirements are generalized over a larger population. However, such approach poses risks of biases, such as sampling (e.g. consulting only expert users as requirements sources), and data collection method (e.g. utilizing only quantitative surveys). Wilson (2006) argues that triangulation and use of multiple methods, measures and approaches must be explicitly interweaves in requirements elicitation process. He argues, that the best results can be achieved by mixing qualitative and quantitative methods, and using multiple complimentary data sources.

Karlsson et al. (2007) report that technology focused companies often neglect user feedback in favor of inventing requirements internally. This is partly due to difficulties obtaining feedback on a new product that is unknown for a market, and partly due to focus on technology rather than actual customer needs (Karlsson et al. 2007). The reports suggest that start-ups often use interviews to elicit requirements from users, however users are not always able to articulate their needs. Davis et al. (2006b) identify four typical situations in requirements elicitation and argue that each requires specific elicitation techniques. For example, if a user and the analyst share knowledge about a specific requirement, simple questioning to verify the requirement could be sufficient. However, if a requirement is unknown to both sides then mutual exploration of the problem and requirements discovery are a more suitable approach to elicitation (Davis et al. 2006a). This resonates very well with findings by Kujala (2008) arguing that it is beneficial to empower and involve a group of key customers in daily development activities.

\subsubsection{Requirements Prioritization}

Requirements prioritization is a requirements analysis activity to categorize requirements by how essential they are for meeting overall goals of the product. The requirement priorities need to be balanced against resources, time and other constraints (IEEE 2014).

Requirements prioritization is discussed most commonly in relation to identifying features for the smallest viable feature set, i.e. a minimum viable product (MVP) (Junk 2000). The MVP is reported as useful to showcase the main advantages of the product to users and to spot inadequacies in product features or design early $\{\mathrm{C} 75-17, \mathrm{C} 14-11\}$.

The reports indicate that customers, own ideas, competitors and similar sources provide a constant flow of ideas for new features and improvements. However, due to resource limitations, only a few can be implemented. Start-ups report on selecting features that deliver 
the most value to their customers. However, this process is reported as difficult without mentioning any specific practices $\{12-110,14-27,15-25,33-6,43-6,48-9,50-9,52-6\}$.

Requirements prioritization is reported as challenging, specifically the selection of prioritization criteria. To maintain a product focus and to stay within resource, time and quality constraints, the company must prioritize what features are the most relevant to deliver a promised value proposition $\{\mathrm{C} 50-11, \mathrm{C} 50-11, \mathrm{C} 57-12, \mathrm{C} 71-24\}$.

Some companies reflect that their challenges with requirements prioritization originate from a vague value proposition, i.e. unclear product goals and benefits. The reports suggest that consequences of poor requirements prioritization are over-scoped product releases and wasted resources on implementing unwanted features $\{C 76-5,50-18,69-14,79-48\}$.

Discussion As illustrated in Fig. 9, requirements prioritization goals are defined by the product value proposition.

Quantifying value is a complex task and often involves making a compromise between interests of different stakeholders. When maximizing value is used as a prioritization goal, different perspectives of value need to be considered. Khurum et al. (2012) propose a breakdown of software value aspects therefore enabling discussion about different perspectives on value.

Lehtola et al. (2005) identifies a need for alignment between business and engineering activities in a market-driven setting. The authors discuss use of roadmapping as a technique to align product and market perspectives. A road-map helps to connect immediate engineering goals with higher level objectives and to facilitate the discussion between different stakeholder perspectives, i.e. customers, business and engineering.

\subsubsection{Release planning}

Release planning is closely related to requirements prioritization and concerns the identification of sets of requirements that can be delivered to customers and provide competitiveness in the market (Carlshamre and Regnell 2000). In a market-driven setting there is a constant pressure to deliver features faster (Giardino et al. 2014). However practical challenges, such as requirements interdependencies, need to be resolved.

When planning product releases, start-ups follow two general approaches: frequently releasing small increments and delivery of a fully-fledged product. The frequent delivery approach starts by creating a very simple functionality, even mock-ups, and continues until the product matures. A continuous delivery process allows to conduct continuous requirement validation and to immediately adjust the product direction $\{\mathrm{C} 33-33, \mathrm{C} 48-4, \mathrm{C} 53-46$, C54-9, C54-11, C87-60, C46-13\}. Fully-fledged releases take more time to build, thus continuous validation of the product direction is challenging. Moreover, as validation takes place after the release, substantial effort is put on risk to be wasted $\{\mathrm{C} 14-11, \mathrm{C} 14-42, \mathrm{C} 52-$ 20, C78-19, C78-20, C87-60, C46-13\}. Attempts to launch a fully-fledged version are most commonly discussed in relation to neglect of user input and focus on technology rather than an actual customer need $\{\mathrm{C} 14-11, \mathrm{C} 14-42, \mathrm{C} 52-20, \mathrm{C} 78-19, \mathrm{C} 78-20, \mathrm{C} 87-60, \mathrm{C} 46-13\}$.

Due to market pressure or internal uncertainty of what customers expect from the product, companies desire to satisfy customers with a more complete and polished product. However, implementation of more features or higher quality requires more resources and postpones the opportunity to demonstrate the product to users, thus hindering requirements validation activities. Companies that have leveraged on early user feedback and have launched a less complete product, report fewer difficulties in marketing the product $\{\mathrm{C} 35-23$, C50-11, C52-20, C57-12, C71-24, C75-17, C75-18, C76-5, C78-19, C82-12, C86-11\}. 
We found that companies often overscope their releases aiming to deliver a more "ground-breaking" product in hopes for more positive user feedback \{C14-11, C52-20, C46-13, C78-19, C87-60\}. As Company \#59 states:

"We should have concentrated on the core idea and launched a Minimum Viable Product (MVP) to test the concept, as we initially had planned even though we never had heard of the concept of an MVP. We kept building more features, since we always felt that 'the service needs X because Flickr has it too' or 'he/she said he needs that feature'."

Overscoping could be a consequence of poor requirements prioritization.

Discussion As illustrated in Fig. 9, release planning is closely related to requirements prioritization and requirements validation. Prioritization provides means for identifying requirements to be included in a product release. Requirements in the release are demonstrated to customers and, thereafter, validated by customer feedback.

Bjarnason et al. (2010) recognize that scoping of product releases is challenging. They report that an unclear vision of overall goals, constant inflow of requirements, and miscommunication are some of the reasons for over-scoping the releases (Bjarnason et al. 2010). As shown by the experience reports and supported by Bjarnason et al. (2010), consequences of over-scoped releases are unmet customer expectations, wasted effort and delays.

Dahlstedt et al. (2003) and Alves et al. (2006) report that in market-driven requirements engineering most requirements validation takes place after the product is released to the users. Therefore, frequent releases enables early identification of potential flaws in the value proposition or the requirements.

Incremental delivery of the product and frequent adjustment of plans are described as key practices of Scrum (Rising and Janoff 2000). Rising and Janoff (2000) reports that organizing development in sprints and prioritizing features for upcoming release helps to deal with uncertainty and changing requirements. Moreover, the Scrum method implies that after each iteration an assessment of progress, user feedback and re-prioritization of tasks takes place. Such rigorous approach to development and planning helps to break down the product to manageable chunks and progress is made even if requirements change. Predictable timing and scope of product releases encourages users to adopt the product (Rising and Janoff 2000).

\subsubsection{Requirements validation}

Requirements validation covers practices to ensure that engineers have understood the requirements and the proposed solution actually solves the original problem (IEEE 2014).

The reports suggest that start-up companies aim to focus their activities around continuous requirements validation. The most commonly discussed technique is to implement requirements in a early version of a product, i.e. a prototype, demonstrate it to the users and to collect feedback, commonly called a feedback loop \{C01-47, C14-8, C29-3, C35-20, C52-22, C54-9, C55-16, C61-7, C71-23, C75-18, C86-14, C87-56, C34-4, C46-13\}.

User feedback is used both to validate the requirements and to identify new user requirements for the product. In addition, interviews with users are reported as useful to review and discuss the requirements before prototyping \{C02-11, C06-6, C14-8, C29-33, C63-13, C34-2\}.

The companies report on using various metrics to gather quantitative data how customers use the product. The collected metrics are used to validate requirements and to steer further product development $\{\mathrm{C} 1-66, \mathrm{C} 48-5, \mathrm{C} 50-18, \mathrm{C} 53-72, \mathrm{C} 57-12, \mathrm{C} 64-17, \mathrm{C} 75-10\}$. 
However, many companies have failed to establish the feedback loop either due to the lack of an internal engineering process to manage user feedback or the difficult access to users \{C49-21, C50-18, C34-2, C86-10\}. As Company \#14, building a software tool for ordering photo prints on-line, reflects:

"Iterations took longer than planned for us, because small print labs were often quite busy and did not have time to immediately have a look at the new version and give feedback. [..] When they finally had time to try out the new version, if they felt that it still needed improvement or they came up with a new feature that would be needed, the launch was likely to be postponed by at least a month."

Discussion As shown in Fig. 9, requirements validation in start-ups is closely related to release planning and provides an input to planning activities. Release planning determines what features are released and, therefore, undergo validation. Outcomes from the validation are used to adjust further product direction.

The most recurring issues in requirements validation are the lack of a structured process to utilize user feedback and the inability to select relevant metrics. However, the experience reports offer little details on specific practices addressing these issues. Our findings are consistent with Olsson and Bosch (2015) who identify similar issues in established companies developing software-intensive products.

Hanssen and Fægri (2006) report on involving expert users in a deploy-test-evaluate loop. The expert users are central in testing and evaluating each release. However, the authors also emphasize the required overhead to maintain the user-developer relationship, to keep the users engaged and to make strategic decisions on the product direction.

Further research is required to understand how to identify users to be involved in development process and to what extent methods by Hanssen and Fægri (2006) could be applied in start-ups.

\subsection{Software design knowledge area}

Software design is a set of activities and a result of defining software architecture, components, interfaces and other characteristics of the system, supporting its construction. Software design can take place before the construction process as in plan-driven contexts, or interweave with the construction process as in an agile setting (IEEE 2014; Yang et al. 2016).

As shown in Fig. 7, most (22 out of 34) statements associated with the Software Design knowledge area lack details for mapping to subcategories. The remainder of the statements specifically discuss the User Interface Design subcategory.

The reports offer very little information on the actual construction of the product, coding or integration of components. Instead, the reports discuss design decisions behind selecting one or another construction technology, components or design goals.

Statements from the reports suggest that start-ups aim to release their products or services fast, thus spending little time on upfront software design. Start-ups opt for incremental designs and faster product releases $\{47,3101,3956\}$. Scalability and flexibility of the product are identified as primary goals of software design $\{264,1245,1836,1922,2982,3249$, $3956,1305,733,1166\}$.

Start-ups report on attempts to leverage on cutting-edge technologies with the aim to gain a competitive advantage such as faster time-to-market or additional features. However, new technologies are often reported as immature causing product quality issues. As Company \#3 states 
"Sure, it was seven years ago, pre-iPhone and pre-Android, so it was ahead of its time, we had to use Adobe Flash on a browser which sucked in so many ways I can't even start to explain how bad it was. Technology would be so much better and more important all mobile today."

Selection of technology also concerns third-party solutions that can be integrated and configured to constitute the product. Third-party components are used as a method to deliver functionality with little development effort. Leveraging on existing functionality of thirdparty components is reported as a key practice in software design. Some companies that have not leveraged on third-party components admit lack of skill and experience in software design $\{$ C04-23, C69-12\}.

Several reports mention good product user experience as an important quality and their efforts to improve it. However, no specific practices regarding user experience engineering are mentioned $\{6-11,14-15,35-17,66-35,63-54\}$. User interface design is recognized as having an impact on customer behavior and attitude toward the product. As Company \#66 reflects on user interface and user experience design:

"The team never properly sat down and brainstormed the UX. Quick decisions were made to get the MVP out the door and these had serious impacts on how the product was received by customers."

Constantinides et al. (2010) and May (2012) also recognize the importance of user interface and its impact on product adaptation.

Other goals of user interface design are the development of a product's visual appeal, to establish a brand identity, to gain attention from media $\{\mathrm{C} 02-87, \mathrm{C} 33-36, \mathrm{C} 67-13\}$, search engine optimization $\{\mathrm{C} 17-16\}$, and promoting viral effects in social networks $\{\mathrm{C} 66-35\}$. An iterative approach of frequently updating the user interface and measuring changes in the user behavior is reported as a viable practice to build user interface of a product $\{\mathrm{C} 01-47$, C02-80, c12-126, C14-33, C33-33, C52-19, C82-13, C46-13, C54-29, C63-06, C02-81\}.

The reports suggest that start-up companies use brainstorming \{C66-42\}, mock-ups and wire-frames $\{\mathrm{C} 14-15\}$ to design user interfaces of a product. Frequent iterations $\{\mathrm{C} 33-36\}$, experiments $\{\mathrm{C} 66-35\}$ and usability tests $\{\mathrm{C} 14-15\}$ are applied to continuously improve the user interface $\{\mathrm{C} 02-87, \mathrm{C} 35-36, \mathrm{C} 61-17, \mathrm{C} 66-35\}$.

However, under a tight schedule, the process could be abandoned and user interface designs are done in a hurry with little consideration $\{\mathrm{C} 14-15\}$ causing quality issues later. Attempts to salvage a product that is unsuccessful for other reasons by tweaking the user interface leads to wasted resources with little or no gain $\{\mathrm{C} 02-87, \mathrm{C} 14-15, \mathrm{C} 63-54\}$.

Discussion The reports suggest that when the understanding of requirements is vague, it is useful to put together a quick prototype demonstrating a feature in question. The prototype is used to gather user feedback before any extensive development takes place $\{\mathrm{C} 33-14, \mathrm{C} 57$ 26, C71-18, C78-25, C79-50, C79-115\}. However, sticking more features into a makeshift product degrades the architecture and technical debt accumulates over time. Maintaining a manageable level of technical debt and creating an architecture supporting changing requirements and enabling quick prototyping is a major challenge \{C04-58, C14-12, C22-04, C33-42, C50-11, C58-15, C64-31\}.

Software design activities in start-ups are closely related to requirements engineering. Non-functional requirements determine the required level of quality as an input for software design activities. However, vague or invented non-functional requirements could lead to under or over-engineering of a product $\{\mathrm{C} 04-22, \mathrm{C} 04-71, \mathrm{C} 23-3, \mathrm{C} 75-23, \mathrm{C} 55-14\}$. 
Quality requirements constraining internal aspects of the product, such as time-to-market or maintenance costs, are repoted as often overlooked. Poor or neglected quality requirements may create pitfalls in the long run: inadequately high maintenance costs when product is launched or overly long release cycles $\{\mathrm{C} 04-22, \mathrm{C} 04-71, \mathrm{C} 23-3, \mathrm{C} 75-23, \mathrm{C} 55-14, \mathrm{C} 32-3$, C78-25, C35-22, C79-115\}.

Creating software design that requires minimal lead time and can accommodate changing requirements while maintaining high product quality is a challenge. The reports suggest that it takes skilled engineers to build such designs and reflections on how inadequate engineering skills had contributed to poor design leading to poor product quality $\{\mathrm{C} 79-50, \mathrm{C} 75-23$, C53-68, C72-18, C73-40, C01-02, C02-80, C35-52, C43-17, C49-26, C52-19, C67-33\}.

A study by Woods (2015) suggests that goals of software architects often clash with goals of agile teams, however there are simple principles that allow both to benefit from each other. For example, breaking the software into smaller components and delivering incrementally helps to avoid large upfront designs. Communicating architecture principles to the developers help the team members to understand why architectural structures exist and what are most important characteristics of the architecture. Yang et al. (2016) identifies forty three software architecture approaches that can be used in an agile context. The identified approaches range from naive (considering architecture only for current iteration) to use or architectural design patterns and cost-benefit analysis.

State-of-the-art in agile software architecture offers a variety of practices and guidelines that could be relevant for start-ups. However, it needs to be explored which exact practices are most efficient to address start-up specific challenges.

\subsection{Software engineering professional practice knowledge area}

The software engineering professional practice knowledge area comprises skills, knowledge and attitudes that an engineer must posses to practice software engineering (IEEE 2014). The reports discuss various aspects of professional practice, such as decision making, motivation, trust, importance of good software engineering skills, and ability to learn.

Difficulties in communication are discussed as having a significant impact on decision making, motivation, trust and general climate in the team. As Company \#79 describes the communication between co-founders:

"Overall, the most important [challenge] is that Nathan and I had difficulty communicating

in a way which would allow us save the company, and that this really drained out motivation."

The reports contain descriptions of team structures ranging from hierarchical to flat. In a start-up team the highest authority are founders. However, some founders empower and involve other team members in making important decisions while others exercise autocracy in all aspects of their companies \{C01-46, C12-54, C62-17, C74-40, C78-17\}.

Autocracy is discussed in the reports as a cause and consequence of lack of trust between team members, miscommunication of company goals and lack of transparency in decision making. However, involving the whole team in every decision hinders performance and team motivation. Separating areas of responsibility and empowering team members to make decisions are discussed in the reports as viable practices for decision making \{C05-06, C12-83, C16-08, C17-19, C46-05, C66-42, C69-04, C71-13, C74-40, C77-22, C78-17, C84-12\}. Company \#17 points out that in a dynamic start-up environment it is difficult to make decisions based on previous experience. Instead decisions should be based on data and experimentation: 
"No one has any idea what is going to work and what's not. Don't listen to the people who think they know. Sure, this one didn't pan out, but each failure helps us navigate the thousands of decisions we will need to make for the next one. That knowledge helps us build better things that will last longer.'

Mutual trust between team members is reported as an important factor for good teamwork and decision making. Founding teams with joint previous experience reflect on team issues more positively and reflect on mutual trust as a contributing factor to good teamwork. The inability to communicate mutual expectations, intentions and motivate own decisions hinders trust \{C49-26, C62-19, C72-18, C73-32, C73-34\}.

Capabilities to learn new emerging practices, adapt to an uncertain environment and collaborate are reported as essential in a start-up environment. Some reports discuss how unanticipated personality traits have contributed to team break-up and company collapse, suggesting that good team composition is essential in start-ups \{C02-47, C14-2, C21-17, C29-4, C73-32, C46-5\}.

A working environment encouraging communication and collaboration, such as a dedicated office space and joint activities, boosts performance and increases motivation \{C56-16, C61-65, C71-14, C73-9, C73-34, C77-22\}. Working remotely is reported to have negative effects in the long term $\{\mathrm{C} 21-14, \mathrm{C} 75-15, \mathrm{C} 77-3\}$, however, when done with consideration, working remotely can have positive effects, i.e. to avoid disturbances in the office $\{\mathrm{C} 75-12\}$ or being closer to the target market $\{\mathrm{C} 01-45, \mathrm{C} 21-14\}$.

The reports discuss how initial optimism for fast success vanishes and development tasks shift from inventing the product to less exciting activities such as handling customer service $\{\mathrm{C} 02-50, \mathrm{C} 02-74, \mathrm{C} 04-20, \mathrm{C} 04-22, \mathrm{C} 77-3\}$. When a critical motivator is not present anymore, a team member may leave the company or start following his own agenda $[\mathrm{C} 01$ 28, C12-142, C21-16\}. Motivation to work in a start-up is often discussed in the reports in relation to shared goals and vision. A lack of shared understanding about changing goals is reported as a consequence of poor value propositions \{C01-58, C12-142, C22-07, C53-86, C71-14, C74-40, C76-06. C77-16, C79-18\}.

Due to time constraints, start-up companies choose people that fit the team by "character rather than skill" $\{$ C63-6, C73-34, C76-6\}, implying that one's commitment and teamwork skills are more important than technical skills.

The reports discuss emotional issues of working in a start-up. Taking responsibility of many tasks at once creates anxiety, leading to burnout and loss of motivation. The reports suggest that the founders loss of motivation to continue operating a start-up, leads also to the end of the company. Anxiety and burnout are also reported as outcomes and poor work and personal life balance $\{\mathrm{C} 01-18, \mathrm{C} 27-35, \mathrm{C} 73-8\}$.

Software engineering is an inherently human and team based intellectual activity. Team factors have emerged as critical in many different development environments and have effect to nearly any other activity (Fagerholm 2012; Khan and Spang 2011; Chow and Cao 2008; Sudhakar 2012; Carmine et al. 2016). However, as shown in Fig. 9, the reports suggest that software design is the most affected software engineering knowledge area. Difficulties in communication, inadequacies in skills and decision making are exposed through suboptimal software design and poor product quality. This finding is consistent with Carmine et al. (2016) reporting that team's disregard of structures and engineering processes lead to deterioration of product architecture.

Fagerholm et al. (2015) reports a study on different factors affecting developer performance in lean and agile environments. In this study performance is used to benchmark efficiency and effectiveness of a team. They explore different factors facilitating 
performance, creating performance awareness, disrupting performance and others. This study shows that there are few key factors contributing to good developer experience. For instance, control of own work, decision power, and good environmental atmosphere contributes positively to overall team performance. Several factors, such as open office, collaboration and competition, and subordinance can both enhance and worsen a team performance.

De Melo et al. (2013) explores agile team productivity and lists several team related processes contributing to productivity, staff turnover and commitment. For example, good conflict management, sharing of expertise, and team coordination are essential to high developer commitment, low staff turnover and high productivity.

As exemplified with these two studies, state-of-the-art identifies the key ingredients for high performing teams in agile and lean environments. The same factors could be applicable in start-up teams. However, start-ups face certain specific limitations in team formation. Firstly, start-ups are founder centric and team environment highly depends on dynamics between the founders (Criaco et al. 2014). Secondly, lack of resources limit access to highly skilled individuals, especially in the early stages. This could lead to sub-optimal initial team composition, and more effort is required to develop the team as a whole to reach the desired performance level (Fagerholm et al. 2015; Carmine et al. 2016).

\subsection{Software Quality knowledge area}

Software quality is a multi-faceted concept in software engineering. Nearly all other knowledge areas aim to somehow contribute to software quality (IEEE 2014). Kitchenham and Lawrence (1996) identifies five perspectives on quality: transcendental, user, manufacturing, product and value-based view.

Figure 5 illustrates that little details are provided in the reports regarding software quality. Superficial statements indicate that start-up companies see software quality as product's characteristics to meet users needs, thus focusing on the user perspective of quality (Kitchenham and Lawrence 1996). The reports discuss usability, especially performance, user experience and reliability as their focus areas $\{\mathrm{C} 50-15, \mathrm{C} 50-22, \mathrm{C} 61-17, \mathrm{C} 67-23$, C67-26, C67-32, C78-15, C86-13, C86-14, C87-22, C37-4, C46-10\}.

The reports reflect on issues stemming from product quality: poor product reception due to an insufficient level of quality, or emphasis on the wrong quality aspects (for example, scalability over time-to-market) $\{$ C14-15, C63-54, C66-35, C54-35, C69-12 \}.

Poor product adoption or loss or reputation are reported as consequences of poor product quality. However, very little details are provided on quality requirements and on any quality assurance procedures.

Discussion While start-ups discuss very little how to achieve software quality, the consequences of inadequate quality, such as ruining the product's image or overly expensive product maintenance, are discussed. We observed that software quality is more discussed in closed companies. This tendency suggests that the importance of software quality may be realized only in hindsight. However, we could not confirm any statistically significant connection between company outcome and statements pertaining software quality.

As shown in Fig. 9, quality originates from product design. The analysis of the reported software design practices in Section 5.3 reveals that companies often put excessive resources on improving certain quality attributes with little market need. The analysis of the reported requirements engineering practices in Section 5.2 shows that there is little discussion on 
quality requirements. Moreover, no practices to assure quality requirements were identified (see Section 5.7).

These findings indicate a gap between requirements engineering and software design. We argue that vague and wrongly prioritized quality requirements contribute to inadequate product design affecting the product's potential to deliver the promised value.

Regnell et al. (2008) argue that in a market-driven context, product quality aspects have different thresholds. If a quality indicator is below a certain threshold, a product is useless. Within certain thresholds the product is useful but does not differentiate itself from competition. Above a certain threshold the product becomes competitive and at some point the quality becomes excessive and costly (Regnell et al. 2008). The concept of quality thresholds enables a company to identify important quality indicators and to perform requirements elicitation to determine the threshold values. Understanding of the threshold values and multiple perspectives of value enables the company to set and specify quality goals. Azar et al. (2007) propose a lightweight method to balance multiple influences to quality requirements and to determine optimal product quality goals. As elaborated in Section 5.3, companies often fail to determine the required level of quality and waste resources on excessive quality features. More research is required to understand to what extent value-oriented requirements engineering practices could be applied in start-ups.

\subsection{Software Engineering Management knowledge area}

The engineering management knowledge area concerns organizational aspects of software engineering, such as initiating, planning, monitoring, controlling and reporting of software engineering activities (IEEE 2014). While the dynamic environment in start-ups makes any detailed plans outdated quickly, the engineering process still must be controlled, follow resource and time constraints, and produce a result that is aligned with overall goals of the company.

With respect to the software engineering management knowledge area, the reports discuss effort estimation, monitoring and product discontinuation practices.

The reports suggest that the companies aim to achieve certain business goals, either to qualify for further external funding or to establish sufficient cash-flow to support development efforts. Pursuing these goals require investments in product development. Thus, estimation of the required resources is an important step to assess feasibility of the goals. The reports discuss how overly optimistic estimates contribute to the collapse of a company due to the lack of resources to finish the product $\{\mathrm{C} 29-35, \mathrm{C} 66-35, \mathrm{C} 77-5, \mathrm{C} 79-11, \mathrm{C} 79$ $120\}$ or missed market opportunities $\{\mathrm{C} 29-35, \mathrm{C} 79-11\}$. However, the reports do not discuss any specific effort estimation method.

The start-ups report that any initial plans are based on assumptions $\{\mathrm{C} 01-77, \mathrm{C} 02-74$, C06-8,C52-30,1967-1978,C24-12\} and are adjusted as data from requirements validation comes in \{ C39-9, C06-6, C82-7, C50-8, C57-18, C34-5, C65-21, C65-14, C35-22, C1447, C66-20, C37-12, C61-10, C61-21, C61-17, C29-40, C33-27, C04-92, C53-110, C54-33, $\mathrm{C} 02-75, \mathrm{C} 02-91\}$. Feedback from customers helps to determine the next immediate step, e.g. to improve certain features or collect feedback from a different stakeholder group. Even though the companies frequently refer to adjusting their plans based on success of a product release, we found very little details about this process $\{\mathrm{C} 01-43, \mathrm{C} 12-142, \mathrm{C} 22-04, \mathrm{C} 02-32$, C29-07, C33-44, C52-08, C52-20, C53-50, C46-13, C60-40, C82-16, C86-10, C51-12\}.

The reports suggest that start-ups attempt to estimate their progress by looking at various metrics that should be carefully selected and tied to business goals. Measuring the wrong thing or measuring too many things may lead to data overload and difficulties to interpret 
many conflicting measurements \{C01-66, C02-93, C05-5, C14-13, C29-25, C33-46, C3526, C48-5, C50-18, C57-12, C64-17, C74-36\}. As Company \#50 reflects on selecting KPI:

"As a business leader you need to figure out the metric that matters most for your company and understand that the more you measure, the less prioritized you'll be. Don't fall into the trap of trying to measure everything."

The reports discuss different approaches to product discontinuation. Companies with products that had attracted a significant number of users report a timely notification to the users about the product discontinuation, and instructions on how to back-up their data and migrate to different solutions $\{\mathrm{C} 18-4, \mathrm{C} 47-6\}$. Some companies leave the product accessible but cease any further development or maintenance efforts $\{\mathrm{C} 05-7, \mathrm{C} 10-15, \mathrm{C} 32-4, \mathrm{C} 36-5\}$. Few companies report open-sourcing the product $\{\mathrm{C} 80-13, \mathrm{C} 65-41\}$.

The reports suggest that decisions stemming from engineering management influence release planning, e.g. by determining the release strategy, and requirements prioritization by setting prioritization goals. Engineering management also influences the professional practice knowledge area by setting expectations and constraints on the engineering team.

Discussion Shahin and Mahbod (2007) proposes criteria for defining organizational goals and a structured method to select key performance indicators for assessing progress toward said goals. A combination of SMART (Specific, Measurable, Attainable, Realistic and Timely) criteria to define goals and analytical hierarchy process (AHP) to select metrics to assess progress toward the goals (Shahin and Mahbod 2007) is a feasible alternative to the "gut feeling" approach described by Olsson and Bosch (2015) and Terho et al. (2015).

Terho et al. (2015) argue that fundamental changes to the start-ups' business plans, i.e. pivoting, are largely based on a gut feeling and are caused by an urgent need, e.g. need for more revenue. However, the collection on operational data (key performance indicators) helps to make more motivated decisions with specific goals (Terho et al. 2015). Therefore, use of a structured method to select important metrics, for example Shahin and Mahbod (2007), could improve decision making in start-ups.

Garengo et al. (2005) report that the lack of resources, little attention to formalization and a reactive approach are factors that hinder implementation of performance indicators in small and medium enterprizes. Cocca and Alberti (2009) argue that key performance indicators are essential to make informed decisions and propose best practices in implementation of performance indicators. The study lists qualities of a good performance indicator and exemplifies maturity grids as a tool to in decision making. Shahin and Mahbod (2007) propose a lightweight technique based on the analytical hierarchy process (AHP) to select and prioritize key performance indicators. These practices for selecting and implementing key performance indicators could be considered for adaptation in start-ups (Shahin and Mahbod 2007; Cocca and Alberti 2009).

Giardino et al. (2014) emphasize the uncertainty in the start-up environment and argue that development teams in start-ups are formed by low-experienced engineers. The lack of joint and individual experience makes the application of expert judgment based effort estimation methods difficult (Molokken and Jorgensen 2003). Usman et al. (Usman and Mendes ) report that the most widespread effort estimation technique in agile teams is planning poker, and the most popular size metric is story points. Moreover, the most common planning levels are current iteration and release. Whether the same methods are equally widespread in start-ups as well requires further research. However, group estimates, i.e. planning poker, is reported as being more accurate than individual estimates and could be very well applied in start-ups (Haugen 2006). 
Existing literature presents very little discussion on software product discontinuation. Jansen et al. (2011) presents a structured plan on how to discontinue a software product. The proposed plan includes adequate pre-planning, transferring customers and partners to another solution and finally reallocation of the product team. Given the lack of resources it is unlikely that start-ups put more than absolute minimal effort on product discontinuation. However, the list of steps to discontinue a product proposed by Jansen et al. (2011) could serve as a roadmap for product discontinuation in start-ups.

\subsection{Software testing knowledge area}

Software testing is the dynamic verification that a product works as expected on a set of selected test cases. Some of the main tasks of testing are to determine what to test, specify input data and expected software behaviors, and to organize the process of software testing (IEEE 2014).

The reports contain only general statements addressing the software testing knowledge area. The statements suggest that start-up companies perform testing activities only when obvious issues emerge. For example, when performance had degraded below an acceptable level $\{\mathrm{C} 24-16, \mathrm{C} 67-26, \mathrm{C} 86-13\}$. Feedback from users is used to spot discrepancies in the product instead of performing rigorous internal testing $\{\mathrm{C} 14-23, \mathrm{C} 29-36, \mathrm{C} 67-26\}$.

Some companies report product failures in operation with substantial loss of resources and reputation. As company \#54 states:

"Finally, the server went down, scuttling the entire operation. Hill started handing out margaritas by the fistful to keep everyone happy. [..] The app picked up a number of

1-star reviews following the debacle".

The reports did not specify whether the failures were due to lack of specific requirements or failure to meet such requirements.

As illustrated in Fig. 9 software testing has a direct impact on software quality. The product must have an acceptable level of quality on all relevant aspects, or the product is simply useless to customers (Regnell et al. 2008).

Discussion Carmine et al. (2016) argue that product quality has a low priority in software start-ups. Instead of rigorous internal testing, start-up companies utilize user feedback to determine if a level of quality is acceptable. A possible explanation is that due to frequently changing or unclear requirements there is no other reliable input for testing (Graham 2002). However, as elaborated in Section 5.5, inadequacies in product quality can severely damage a product's reputation. Therefore, a company must carefully assess the risks stemming from the reliance on user side testing.

Another possible explanation is that a large part of testing is done by developers during the development process. This explains why the product appears to be in shape when released (code defects are removed), however failures in operation indicate a lack of design and stress testing (Runeson et al. 2006). Our findings suggest that start-ups are overlooking a potentially important knowledge area.

\subsection{Software Maintenance knowledge area}

A result of software development is a delivery of a software product to is users. However, post delivery defects may emerge, operating environment change or users could propose new requirements. The software maintenance phase begins when software is released to 
customers and ensures that the software continue to operate as intended. Software maintenance activities fall into perfective maintenance (to improve some quality the software, e.g. performance), corrective maintenance (to remove defects), adaptive maintenance (to adapt the software to a changed environment) and preventive maintenance (to prevent problems before they occur) (IEEE 2014).

Start-up companies report on software maintenance costs $\{\mathrm{C} 23-3, \mathrm{C} 32-3\}$ and resource allocation for maintenance activities. The reports discuss the struggle of performing timely corrective maintenance due to understaffed teams. Long response time to product faults is reported as having a negative impact on product adoption $\{$ C77-3 $\}$. Adaptive maintenance to keep up with the product and any third-party component changes is reported as a concern $\{$ C14-12, C38-9\}.

Discussion The reports contain very little details on how start-ups manage software maintenance. However, inadequately high costs of keeping the product running is reported in relation to poor software design. As discussed in Section 5.3, goals of software design shift from faster time-to-market to reducing maintenance effort. This shift takes place when the product feature set stabilizes and more and more users start-using the product (Crowne 2002).

If this shift is not executed properly, a large number of users can overwhelm the product, exposing any inadequacies in product design and quality. Tackling these inadequacies may require substantial resources and time, contributing to the collapse of the company.

Batista Webster et al. (2005) propose a taxonomy for evaluating risks pertaining to software maintenance. The taxonomy could be used in start-ups to identify and address potential maintenance risks during product development. Tom et al. (2013) argue that taking risks in engineering, i.e. creating technical debt, is a trade-off between shorter time-to-market and internal product quality. However, how exactly technical debt is handled in start-ups and to what extent this taxonomy is exhaustive and relevant in start-up context requires more research (Batista Webster et al. 2005; Tom et al. 2013).

\section{Conclusions and future work}

This study is the largest (by a number of studied cases) and broadest (by addressed software engineering knowledge areas) investigation into engineering aspects of start-ups to-date. With this study we paint a rich picture on how start-ups reflect on utilizing software engineering, what engineering practices start-ups use, and why. This study is aimed to characterize software engineering in start-ups, thus providing the necessary groundwork for conducting further and more detailed investigation into software-intensive product engineering in start-up context. To achieve our goal we perform third level analysis of start-up experience reports from 25 relatively successful and 63 closed start-ups.

Our results show that start-ups apply market-driven requirements engineering practices to discover and validate ideas for innovative products. However, the applied requirements engineering practices are often rudimentary and lack alignment with other knowledge areas. As a consequence, inadequacies in requirements engineering hinder other engineering activities and might lead to unwanted technical debt, poor product quality, and wasted resources on building irrelevant features. Further work is needed to identify good requirements engineering practices in start-ups.

We have found very little discussion regarding software testing. However, the reports discuss disastrous events when a product had failed in hands of customers. We conclude 
that software testing practices could be overlooked by start-ups. Further research is needed to understand state-of-practice in software testing in start-up context.

Other software engineering knowledge areas have a supportive role in continuous requirements identification and validation. For example, software design knowledge must support fast evolution of product prototypes, used to gather customer requirements, to a robust solution for easy maintenance.

The results of this study are intended to be useful to researchers in supporting further research in the area. The results can also be useful to start-up engineers willing to learn from experience of others. We have analyzed our findings in context of related work, thus hinting practitioners toward potentially useful practices. Future work includes examining key knowledge areas in more detail, and exploring to what extent the use of certain practices contributes to achieving start-up goals.

Acknowledgments The authors would like to thank Dr. Krzysztof Wnuk for insightful discussions, comments and hints to related work.

Open Access This article is distributed under the terms of the Creative Commons Attribution 4.0 International License (http://creativecommons.org/licenses/by/4.0/), which permits unrestricted use, distribution, and reproduction in any medium, provided you give appropriate credit to the original author(s) and the source, provide a link to the Creative Commons license, and indicate if changes were made.

\section{References}

Abpmp (2009) Guide to the business process management common body of knowledge. management Abrahamsson P, Nguyen-duc A, Baltes GH, Conboy K, Dennehy D, Sweetman R, Edison H, Shahid S, Wang X, Garbajosa J, Gorschek T, Unterkalmsteiner M, Hokkanen L, Lunesu I, Marchesi M, Morgan L, Selig C, Oivo M, Shah S, Kon F (2016) Software Startups - A Research Agenda. e-Informatica. Softw Eng J 10(1):1-28

Alves C, Pereira S, Castro J (2006) A study in market-driven requirements engineering. Work. em Eng Requisitos WER06, pp 2-3

Ambler S (2002) Lessons in agility from Internet-based development. IEEE Softw 19(2):66-73

Azar J, Smith RK, Cordes D (2007) Value-oriented requirements prioritization in a small development organization. IEEE Softw 24(1):32-37

Bajwa SS, Wang X, Duc AN, Abrahamsson p (2017) failures to be celebrated: an analysis of major pivots of software startups. Empir Softw Eng 22(5):2373-2408

Baskerville R, Ramesh B, Levine L, Pries-Heje J, Slaughter S (2003) Is internet-speed software development different? IEEE Softw 20(2015):70-77

Batista Webster KP, De Oliveira KM, Anquetil N (2005) A risk taxonomy proposal for software maintenance. IEEE Int Conf Softw Maint ICSM 2005:453-464

Bjarnason E, Wnuk K, Regnell B (2010) Overscoping: Reasons and consequences - A case study on decision making in software product management. Softw. Prod. Manag. (IWSPM), 2010 Fourth Int Work, pp 30-39

Blank S (2013a) The four steps to the epiphany, 2nd edn. K\&S Ranch, NY

Blank S (2013b) Why the lean start up changes everything. Harv Bus Rev 91(5):64

Boehm B (2003) Value-based software engineering: reinventing, vol 28

Bosch J, Olsson H, Björk J, Ljungblad J (2013) The early stage software startup development model: A framework for operationalizing lean principles in software startups. In: Lean Enterp. Softw. Syst., chap. The Early, pp 1-15

Broy M (2006) The 'Grand challenge' in informatics: Engineering Software-Intensive systems. Comput (long Beach Calif) 39(10):72-80

Budgen DT, Brereton M, Pearl Kitchenham B (2008) Using mapping studies in software engineering. In: Proceedings of the PPIG, 2008, vol 2, pp 195-204

Carlshamre P, Regnell B (2000) Requirements lifecycle management and release planning in market-driven requirements engineering processes. In: Proceedings - International Working Database Expert Systems with Applications DEXA 2000-Janua (September), pp 961-965 
Carlson CR, Wilmot WW (2006) Innovation: The five disciplines for creating what customers want. Crown Business

Carmel E (1994) Rapid development in software package startups. In: Proceedings 27th hawaii int'1 conference System Sciences

Carmine G, Paternoster N, Unterkalmsteiner M, Gorschek T, Abrahamsson P (2016) Software development in startup companies: The greenfield startup model. IEEE Trans Softw Eng X(September):233

cbinsights.com (2015) https://www.cbinsights.com/blog/startup-failure-post-mortem/

Chow T, Cao DB (2008) A survey study of critical success factors in agile software projects. J Syst Softw 81(6):961-971

Churchill N, Lewis V (1983) Five stages of small business growth. Harv Bus Rev 61(3):30-40

Cocca P, Alberti M (2009) A framework to assess performance measurement systems in SMEs. Int J Product Perform Manag 59(2):186-200

Constantinides E, Lorenzo-Romero C, Gómez Ma (2010) Effects of web experience on consumer choice: a multicultural approach. Internet Res 20(2):188-209

Corbin JM, Strauss A (1990) Grounded theory research: procedures, canons, and evaluative criteria. Qual Sociol 13(1):3-21

Criaco G, Minola T, Migliorini P, Serarols-Tarrés C (2014) To have and have not: founders' human capital and university start-up survival. J Technol Transfer 39(4):567-593

Crowne M (2002) Why software product startups fail and what to do about it. In: Engineering Management Conference. IEEE, Cambridge, pp 338-343

crunchbase.com (2015) https://www.crunchbase.com/

Dahlstedt ÅG, Karlsson L, Persson A, Natt och Dag J, Regnell B (2003) Market-Driven Requirements engineering processes for software products - a report on current practices. In: Int Work COTS prod software, RECOTS 2003

Davis A, Dieste O, Hickey A, Juristo N, Moreno AM (2006a) Effectiveness of requirements elicitation techniques: Empirical results derived from a systematic review. Proc IEEE Int Conf Requir Eng:176-185

Davis CJ, Fuller RM, Tremblay MC, Berndt DJ (2006b) Communication challenges in requirements elicitation and the use of the repertory grid technique. J Comput Inf Syst 46(JANUARY):78-86

De Melo CO, Cruzes SD, Kon F, Conradi R (2013) Interpretative case studies on agile team productivity and management. Inf Softw Technol 55(2):412-427

Deakins E, Dillon S (2005) A helical model for managing innovative product and service initiatives in volatile commercial environments. Int J Proj Manag 23(1):65-74

Dorling A (1993) SPICE: Software Process improvement and capability dEtermination. Inf Softw Technol 35(6-7):404-406

Fabijan A, Olsson HH, Bosch J (2012) Customer feedback and data collection techniques in software R\&D: a literature review. In: Icsob. vol 114, pp 139-153

Fagerholm F (2012) Developer Experience : Concept and Definition, pp 73-77

Fagerholm F, Ikonen M, Kettunen P, Munch J, Roto V, Abrahamsson P (2015) Performance Alignment Work: How software developers experience the continuous adaptation of team performance in Lean and Agile environments. Inf Softw Technol 64:132-147

Feldt R, Angelis L, Torkar R, Samuelsson M (2010) Links between the personalities, views and attitudes of software engineers. Inf Softw Technol 52(6):611-624

Garengo P, Biazzo S, Bititci U (2005) Performance measurement systems in SMEs: A review for a research agenda. Int J Manag Rev 7(1):25-47

Garousi V, Felderer M, Mäntylä MV (2016) The Need for Multivocal Literature Reviews in Software Engineering: Complementing Systematic Literature Reviews with Grey Literature. In: Proceedings of the 20th International Conference on Evaluation Assessment Software Engineering, pp 26:1--26:6

Giardino C, Unterkalmsteiner M, Paternoster N, Gorschek T, Abrahamsson P (2014) What Do We Know about Software Development in Startups? IEEE Softw 31(5):28-32

Giardino C, Wang X, Abrahamsson P (2014) Why Early-Stage Software Startups Fail: A Behavioral Framework, pp 27-41

Giardino C, Bajwa SS, Wang X (2015) Key challenges in Early-Stage software startups. In: Agile Processing of Software Engineering Extremity Programming, vol. 212, pp. 52-63

Graham D (2002) Requirements and testing: Seven Missing-Link myths. IEEE Softw 19(5):15-17

Hague P, Hague N, Morgan CA (2004) Market research in practice: A quide to the basics

Hanssen GK, Fægri TE (2006) Agile customer engagement. Proceedings of the 2006 ACM/IEEE International Symposium on Empirical Software Engineering - ISESE '06, pp 164

Haugen NC (2006) An empirical study of using planning poker for user story estimation. Proc - Agil Conf 2006(2006):23-31 
Hofmann HF, Lehner F (2001) Requirements engineering as a success factor in software projects. IEEE Softw 18(4):58-66

IEEE (2011) ISO/IEC/IEEE 42010 Systems and Software engineering - arcthitecture description 2011

IEEE (2014) Guide to the Software Engineering Body of Knowledge Version 3.0 (SWEBOK Guide V3.0)

Jansen S, Popp KM, Buxmann P (2011) The sun also sets: Ending the life of a software product. Softw Bus 80:154-167

Junk WS (2000) The dynamic balance between cost, schedule, features, and quality in software development projects. Comput. Sci. Dept., univ idaho SEPM-001

Karlsson L, Dahlstedt ÅG, Regnell B, Natt och Dag J, Persson A (2007) Requirements engineering challenges in market-driven software development - An interview study with practitioners. Inf Softw Technol 49(63):588-604

Khan RA, Spang K (2011) Critical Success Factors for International Projects. In: 6th IEEE Int Conf Intell Data Acquis Adv Comput Syst Technol Appl, vol 2, no 10, pp 879-883

Khurum M, Gorschek T, Wilson M (2012) The software value map - an exhaustive collection of value aspects for the development of software intensive products. J. SOFTWARE-EVOLUTION Process (July 2010), pp 481-491

Kitchenham B, Lawrence S (1996) Software quality: the elusive target. IEEE Softw 1(January):12-21

Klotins E, Unterkalmsteiner M, Gorschek T (2015) Software Engineering Knowledge Areas in Startup Companies : a mapping study. In: Lecture Notes Business Information Processing. Springer, pp 245-257

Kujala S (2008) Effective user involvement in product development by improving the analysis of user needs. Behav Inf Technol 27(6):457-473

Lehtola L, Kauppinen M, Kujala S (2005) Linking the business view to requirements engineering: long-term product planning by roadmapping. 13th. IEEE Int. Conf. Requir. Eng. RE05, pp 439-443

Lethbridge TC, Sim SE, Singer J (2005) Studying software engineers: data collection techniques for software field studies. Empir Softw Eng 10:311-341

May B (2012) Applying Lean Startup: An Experience Report - Lean \& Lean UX by a UX Veteran: Lessons Learned in Creating \& Launching a Complex Consumer App. In: Agile Conference, pp 141-147. IEEE

Melegati J, Goldman A, Paulo S (2016) Requirements Engineering in Software Startups: a Grounded Theory approach. 2nd International Work Software Startups, Trondheim

Miller G, Williams L (2006) Personas: Moving beyond Role-Based requirements engineering. Microsoft North Carolina State, pp 1-10

Mitroff II (1983) Stakeholders of the organizational mind, Jossey-Bass, San Francisco

Molokken K, Jorgensen M (2003) A review of software surveys on software effort estimation. 2003 Int. Symp. Empir. Softw. Eng. 2003. ISESE 2003. Proceedings (1325)

Ogawa RT, Malen B (1991) Towards rigor in reviews of multivocal literatures: applying the exploratory case study method. Rev Educ Res 61:265-286

Olsson HH, Bosch J (2015) Towards continuous customer validation: a conceptual model for combining qualitative customer feedback with quantitative customer observation. In: Icsob, vol 114, pp 261-266

Osterwalder A, Pigneur Y, Tucci C (2005) Clarifying business models: origins, present, and future of the concept. Commun Assoc Inf Syst 15:1-43

Pacheco C, Garcia I (2012) A systematic literature review of stakeholder identification methods in requirements elicitation. J Syst Softw 85(9):2171-2181

Paternoster N, Giardino C, Unterkalmsteiner M, Gorschek T, Abrahamsson P (2014) Software development in startup companies: a systematic mapping study. Inf Softw Technol 56(10):1200-1218

PitchBook Data I (2015a) European Middle Market Report 2H 2015

PitchBook Data I (2015b) U.S. Middle market report Q4 2015. Technical report

Product Team CMMI, Team CP (2010) CMMI for Development, Version 1.3. Carnegie Mellon Univ. (November), pp 482

Pronin E, Lin DY, Ross L (2002) The bias blind spot: Perceptions of bias in self versus others. Personal Soc Psychol Bull 28(3):369-381

Pruitt J, Grundin J (2003) Personas : Practice and Theory. Proc. 2003 Conf. Des. user Exp. pp. 115

Rafiq U et al (2017) Requirements Elicitation Techniques Applied in Software Startups. 2017 43rd Euromicro Conference on Software Engineering and Advanced Applications (SEAA), IEEE

Ramesh B, Cao L, Baskerville R (2007) Agile requirements engineering practices and challenges: an empirical study. Inf Syst J 20(5):449-480

Regnell B, Svensson RB, Olsson T (2008) Supporting roadmapping of quality requirements. IEEE Softw 25:42-47

Ries E (2011) c How Today's Entrepreneurs Use Continuous Innovation to Create Radically Successful Businesses, crown busi edn

Rising L, Janoff NS (2000) The Scrum software development process for small teams. IEEE Softw 17(4):26-32 
Runeson P, Andersson C, Thelin T, Andrews a, Berling T (2006) What do we know about defect detection methods? [software testing]. IEEE Softw 23(3):82-90

Runeson P, Höst M, Rainer A, Regnell B (2012) Case study research in software engineering. Wiley, Hoboken

Saldaña J (2010) The coding manual for qualitative researchers

Seaman C (1999) Qualitative methods in empirical studies of software engineering. IEEE Trans Softw Eng 25(4):557-572

Shahin A, Mahbod MA (2007) Prioritization of key performance indicators. Int J Product Perform Manag 56(3):226-240

Sicilia Má, Cuadrado Jj, García E, Rodríguez D, Hilera JR (1990) The Evaluation of ontological representations of the SWEBOK as a revision tool, pp 1-4

Šmite D, Wohlin C, Galvina Z, Prikladnicki R (2014) An empirically based terminology and taxonomy for global software engineering, vol 19, no 1, pp 105-153

Startup Compass Inc. (2015) The global startup ecosystem ranking 2015. Technical Report

Sudhakar GP (2012) A model of critical success factors for software projects. J Enterp Inf Manag Iss Ind Manag Data Syst Iss Charalambos Spat J Enterp Inf Manag 19(1):83-96

Sutton SM, Cubed EC, Andretti M (2000) The Role of Process in a Software Start-up. IEEE Softw 17(4):33-39

Terho H, Suonsyrja S, Mikkonen T (2015) Ways to Cross the Rubicon: Pivoting in Software Startups Henri, pp 555-568

Tingling P, Saeed A (2007) Extreme programming in action: a longitudinal case study. In: HCI International, pp 242-251

Tom E, Aurum A, Vidgen R (2013) An exploration of technical debt. J Syst Softw 86(6):1498-1516

Tovstiga G, Grossmann H (2012) Strategic innovation: Exploring the link between differentiation, learning and innovation failure in start-up enterprises. In: $2 \mathrm{Nd}$ Annual International Conference on Innovations in Entrepreneurship (IE 2012), ie, pp 76

Usman M, Mendes E Effort Estimation in Agile Software Development: A Survey on the State of the Practice Categories and Subject Descriptors

Wilson CE (2006) Triangulation: the explicit use of multiple methods, measures, and approaches for determining core issues in product development. In: Interactions, vol 13, no 6, pp 46-49

Woods E (2015) Aligning architecture work with agile teams. IEEE Softw 32(5):24-26

Yang C, Liang P, Avgeriou P (2016) A systematic mapping study on the combination of software architecture and agile development. J Syst Softw 111:157-184

Yau A, Murphy C (2013) Is a Rigorous Agile Methodology the Best Development Strategy for Small Scale Tech Startups? Technical report University of Pennsylvania Department of Computer and Information Science

Zachman JA (2003) The Zachman framework for enterprise architecture Primer for Enterprise Engineering and Manufacturing.[si]: Zachman International

Zettel J, Maurer F, Münch J, Wong L (2001) LIPE: A Lightweight Process for E-business Startup Companies Based on Extreme Programming, pp 255-270

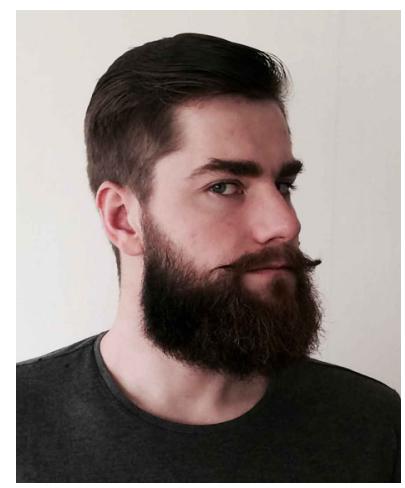

Eriks Klotins is a PhD student of Software Engineering at Blekinge Institute of Technology (BTH). The focus of his thesis is software engineering practices in start-ups and development of a start-up engineering roadmap. He has over nine years of experience in software development projects ranging from large government IT systems to several start-ups projects. Contact him by: eriks.klotins@bth.se. 


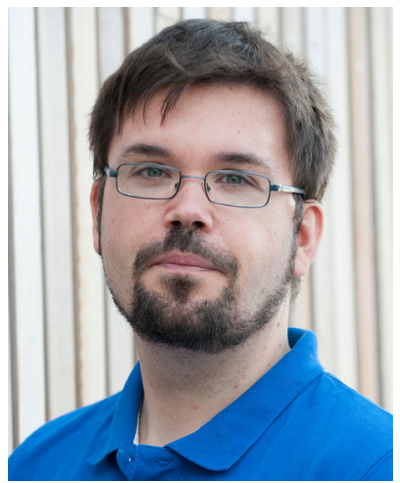

Michael Unterkalmsteiner received the BSc degree in applied computer science from Free University of Bozen-Bolzano in 2007, and the MSc and PhD degrees in software engineering from Blekinge Institute of Technology (BTH) in 2009 and 2015, respectively. He is a senior lecturer at BTH. His research interests include software repository mining, software measurement and testing, process improvement, and requirements engineering. He is a member of the IEEE. For more information or contact: www.lmsteiner.com, michael.unterkalmsteiner@bth.se.

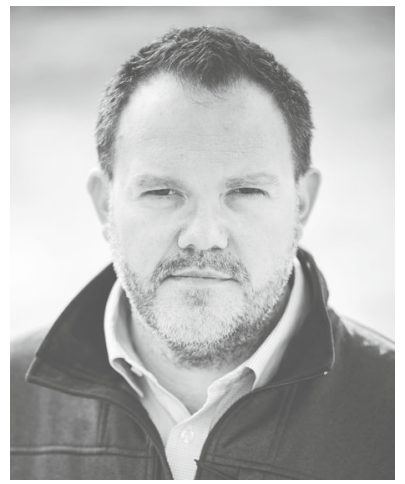

Tony Gorschek is a professor of Software Engineering at Blekinge Institute of Technology (BTH. He has over ten years' industrial experience as a CTO, senior executive consultant, and engineer, but also as a chief architect and product manager. In addition, he has built up five start-ups in fields ranging from logistics to internet-based services. Contact him by: tony.gorschek@bth.se. 